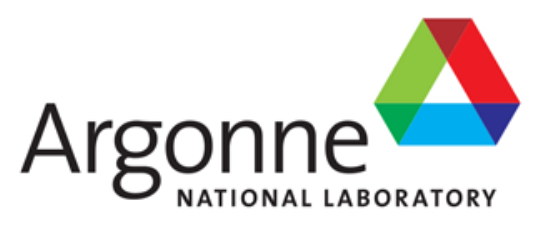

ANL/GSS-15/5

\title{
Literature Review and Synthesis for the Natural Gas Infrastructure
}

Risk and Infrastructure Science Center Global Security Sciences Division 


\begin{abstract}
About Argonne National Laboratory
Argonne is a U.S. Department of Energy laboratory managed by UChicago Argonne, LLC under contract DE-AC02-06CH11357. The Laboratory's main facility is outside Chicago, at 9700 South Cass Avenue, Argonne, Illinois 60439. For information about Argonne and its pioneering science and technology programs, see www.anl.gov.
\end{abstract}

\title{
DOCUMENT AVAILABILITY
}

Online Access: U.S. Department of Energy (DOE) reports produced after 1991 and a growing number of pre-1991 documents are available free via DOE's SciTech Connect (http://www.osti.gov/scitech/).

Reports not in digital format may be purchased by the public from the National Technical Information Service (NTIS):

U.S. Department of Commerce

National Technical Information Service

5301 Shawnee Road

Alexandria, Virginia 22312

www.ntis.gov

Phone: (800) 553-NTIS (6847) or (703) 605-6000

Fax: (703) 605-6900

Email: orders@ntis.gov

Reports not in digital format are available to DOE and DOE contractors from the Office of Scientific and Technical Information (OSTI):

U.S. Department of Energy

Office of Scientific and Technical Information

P.O. Box 62

Oak Ridge, Tennessee 37831-0062

www.osti.gov

Phone: (865) 576-8401

Fax: (865) 576-5728

Email: reports@osti.gov

\section{Disclaimer}

This report was prepared as an account of work sponsored by an agency of the United States Government. Neither the United States Government nor any agency thereof, nor UChicago Argonne, LLC, nor any of their employees or officers, makes any warranty, express or implied, or assumes any legal liability or responsibility for the accuracy, completeness, or usefulness of any information, apparatus, product, or process disclosed, or represents that its use would not infringe privately owned rights. Reference herein to any specific commercial product, process, or service by trade name, trademark, manufacturer, or otherwise, does not necessarily constitute or imply its endorsement, recommendation, or favoring by the United States Government or any agency thereof. The views and opinions of document authors expressed herein do not necessarily state or reflect those of the United States Government or any agency thereof, Argonne National Laboratory, or UChicago Argonne, LLC. 


\section{Literature Review and Synthesis for the Natural Gas Infrastructure}

prepared by

Stephen Folga, ${ }^{1}$ Leah Talaber, ${ }^{1}$ Michael McLamore, ${ }^{1}$ Ian Kraucunas, ${ }^{2}$

Timothy McPherson, ${ }^{3}$ Trevor Manzanares ${ }^{4}$ and Lori Parrott ${ }^{4}$

${ }^{1}$ Argonne National Laboratory

${ }^{2}$ Pacific Northwest National Laboratory

${ }^{3}$ Los Alamos National Laboratory

${ }^{4}$ Sandia National Laboratories

June 2015 



\section{Contents}

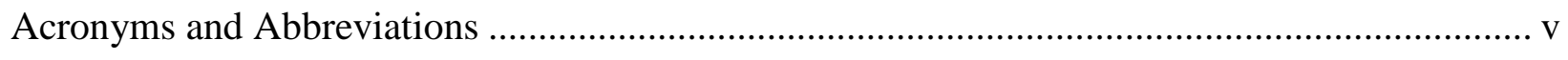

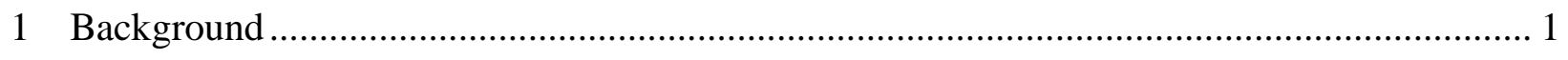

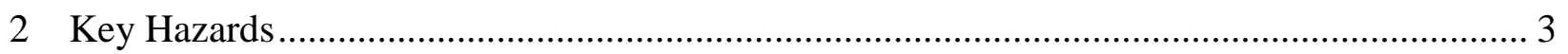

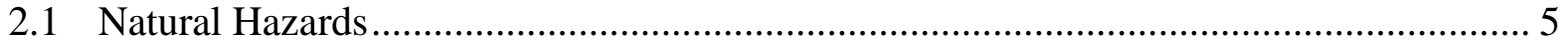

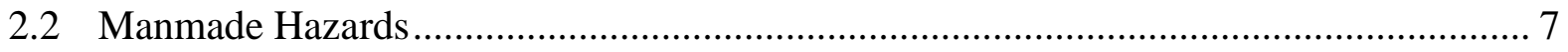

2.2.1 Cyber Attack ……………….................................................................... 9

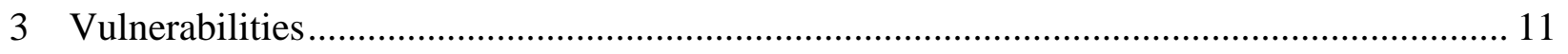

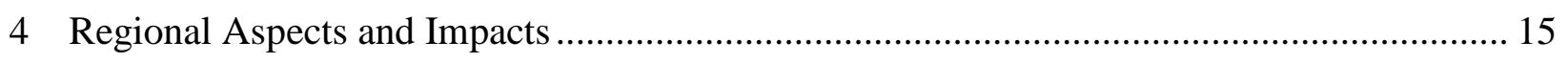

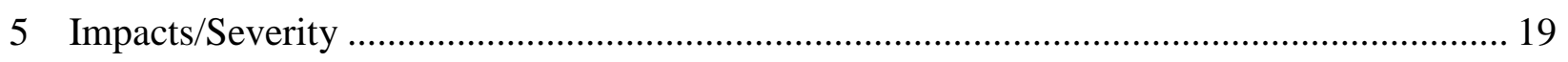

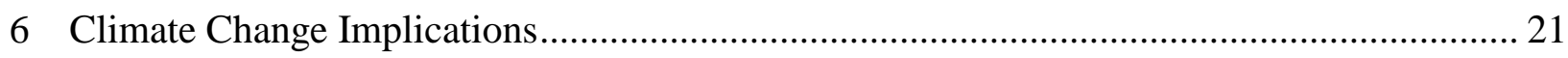

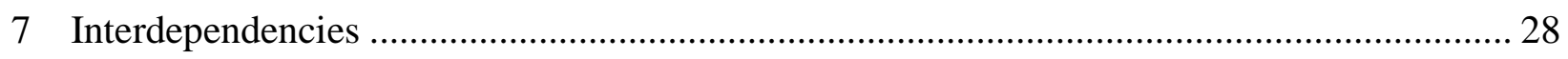

7.1 Energy Infrastructure Context......................................................................................... 30

7.2 Interdependencies among Oil, Natural Gas, and Electric Power ..................................... 31

7.2.1 Electric Power and Natural Gas ....................................................................... 32

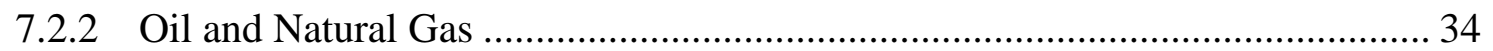

7.2.3 Other Infrastructures and Natural Gas ............................................................. 34

7.3 Case Study of a Disruptive Event: The Big Chill ........................................................... 36

7.4 Case Study of a Disruptive Event: Coordinating Natural Gas and Electric Power........ 37

8 Options for Mitigation, Preparedness, Recovery, and Response.............................................. 39

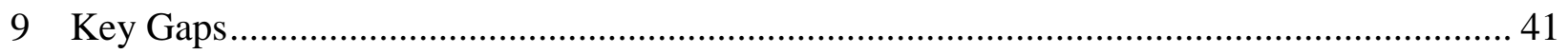

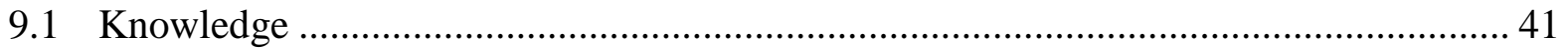

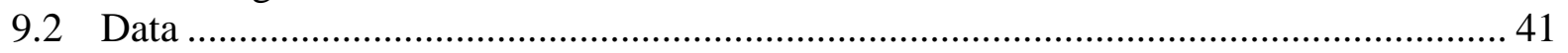

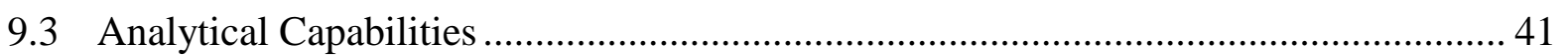

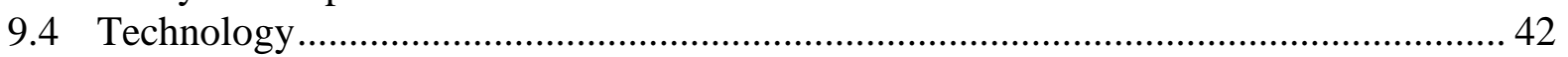

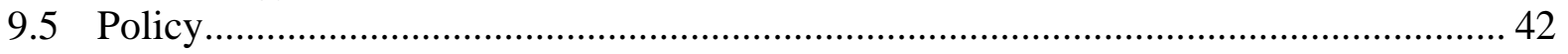

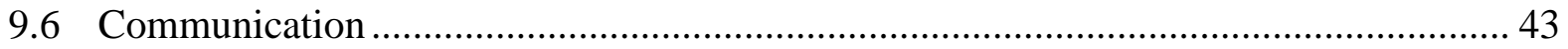

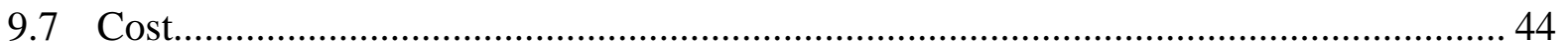

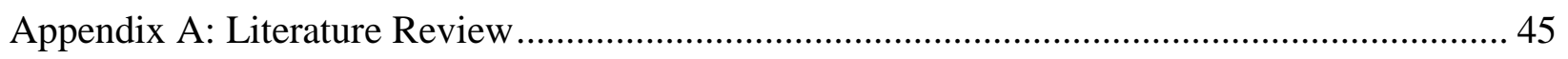

Appendix B: Vulnerability, Impact/Severity Numerical Scale...................................................... 47

\section{Figures}

1 Significant Gas Transmission System Incidents by Cause, 2006-2010 ….............................. 3

2 Significant Gas Distribution System Incidents by Cause, 2008-2010 ..................................... 4

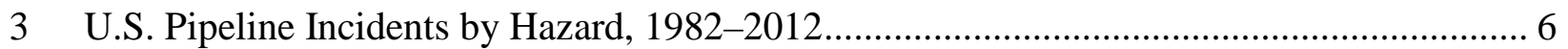

4 Percent of PHMSA Serious Incidents Due to Third-Party Damage to Natural Gas Transmission Pipelines............................................................................................................... 8 


\section{Figures (Cont.)}

5 PHMSA Data on the Number of Natural Gas Transmission Pipeline

Vandalism/Sabotage Incidents by Year in the United States ............................................ 9

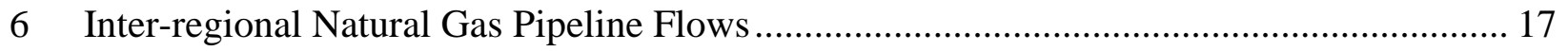

7 Steady Rise of Air-Conditioned Homes ........................................................................ 23

8 Projected Change in Heating-Degree Days at Four Major U.S. Urban Areas ...................... 24

9 Projected Changes in Frost-Free Season Length.......................................................... 25

10 Infrastructure Dependencies and Interdependencies ..................................................... 30

11 Interdependent Links among Oil, Natural Gas, and Electric Power .................................. 31

12 Locations of Electric-Driven Compressor Stations .......................................................... 33

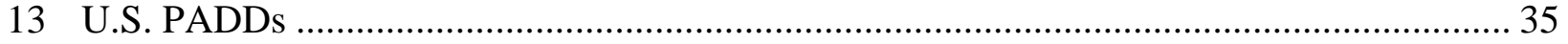

\section{Tables}

1 Hazard Risksa for the Natural Gas Infrastructure ...................................................... 11

2 Regional Net Interstate Pipeline Capacity on a State-to-State Level ................................. 16

3 Hazard Severitya for the Natural Gas Infrastructure ..................................................... 20

4 Hazard Type Relative to Climate Effect .................................................................. 21

5 Principal Interdependency Categories Defined by Rinaldi et al. ..................................... 29

6 Interdependency Categories Defined by Pederson et al................................................. 29

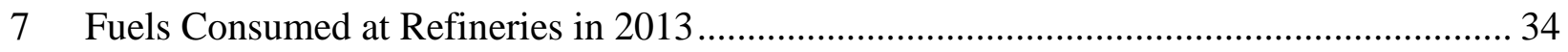




\section{Acronyms and Abbreviations}

\begin{tabular}{|c|c|}
\hline AGA & American Gas Association \\
\hline $\begin{array}{l}\mathrm{Bcf} / \mathrm{d} \\
\mathrm{bpd}\end{array}$ & $\begin{array}{l}\text { billion cubic feet per day } \\
\text { barrel(s) per day }\end{array}$ \\
\hline CNG & compressed natural gas \\
\hline CRS & Congressional Research Service \\
\hline DHS & U.S. Department of Homeland Security \\
\hline DOE & U.S. Department of Energy \\
\hline DOT & U.S. Department of Transportation \\
\hline EIA & Energy Information Administration \\
\hline EPA & U.S. Environmental Protection Agency \\
\hline ERCOT & Electric Reliability Council of Texas \\
\hline FEMA & Federal Emergency Management Agency \\
\hline FERC & Federal Energy Regulatory Commission \\
\hline FHWA & Federal Highway Administration \\
\hline GHG & greenhouse gas \\
\hline $\begin{array}{l}\text { ICS-CERT } \\
\text { IED } \\
\text { IEISS } \\
\text { IPCC }\end{array}$ & $\begin{array}{l}\text { Industrial Control Systems Cyber Emergency Response Team } \\
\text { improvised explosive device } \\
\text { Interdependent Energy Infrastructure Simulation System } \\
\text { Intergovernmental Panel on Climate Change }\end{array}$ \\
\hline LDC & local distribution company \\
\hline LNG & liquefied natural gas \\
\hline LPG & liquid petroleum gas \\
\hline MTPA & million tons per annum \\
\hline $\begin{array}{l}\text { NERC } \\
\text { NGL }\end{array}$ & $\begin{array}{l}\text { North American Electric Reliability Corporation } \\
\text { natural gas liquid }\end{array}$ \\
\hline PADD & Petroleum Administrative Defense District \\
\hline PHMSA & Pipeline and Hazardous Materials Safety Administration \\
\hline SCADA & supervisory control and data acquisition system \\
\hline TS\&D & transmission, storage, and distribution \\
\hline
\end{tabular}


USGCRP U.S. Global Change Research Program

USGS U.S. Geological Survey

VBIED vehicle-borne improvised explosive device 


\section{Background}

The U.S. energy infrastructure fuels the economy of the 21st century. Without a stable energy supply, health and welfare are threatened, and the U.S. economy cannot function. Presidential Policy Directive 21 identifies the Energy Sector as uniquely critical because it provides an "enabling function” across all critical infrastructure sectors. ${ }^{1}$

The efficient and effective movement of natural gas from producing regions to consuming regions requires an extensive and elaborate transportation system. In many instances, natural gas produced from a particular well has to travel a great distance to reach its point of use. The transportation system for natural gas consists of a complex network of pipelines designed to quickly and efficiently transport the gas from its origin to areas of high demand. The transportation of natural gas is closely linked to its storage: If the natural gas being transported is not immediately required, it can be put into storage facilities until it is needed. ${ }^{2}$ A description of the natural gas transmission, storage, and distribution (TS\&D) sector is provided as follows.

The interstate natural gas pipeline network transports the gas from processing plants in producing regions to market areas where the natural gas requirements are high, particularly large urban areas. Compression stations along the pipeline transmission route keep the gas moving at the desired volumes and pressures.

Local distribution companies typically transport natural gas from interstate pipeline delivery points to end users through millions of miles of distribution pipe. Delivery points to local distribution companies are often termed "city gates," especially those for large municipal areas, and they are important market centers for the pricing of natural gas.

Gas is typically stored underground and under pressure as an efficient way to balance variations between supply input and market demand. Three types of facilities are used for underground gas storage: depleted reservoirs in oil and/or gas fields, aquifers, and salt caverns. Facilities serving the interstate market are subject to Federal Energy Regulatory Commission (FERC) regulations; otherwise they are State-regulated. Most working gas ${ }^{3}$ held in storage facilities is held under leases with shippers, local distribution companies, or end users who own the gas.

Liquefied natural gas (LNG) is produced by cooling natural gas to $-260^{\circ} \mathrm{F}\left(-160^{\circ} \mathrm{C}\right)$. In its liquid state and at standard conditions, natural gas occupies 618 times less volume than does the same mass of gaseous methane, which allows it to be transported by specially designed ships or tankers.

1 DOE (U.S. Department of Energy) and DHS (U.S. Department of Homeland Security), 2010. Energy SectorSpecific Plan - An Annex to the National Infrastructure Protection Plan, available at http://www.dhs.gov/xlibrary/assets/nipp-ssp-energy-2010.pdf, accessed September 16, 2014.

2 NaturalGas.org, 2013. "The Transportation of Natural Gas," available at http://naturalgas.org/naturalgas/transport/, accessed September 16, 2014.

3 Working gas is the amount of gas that may or may not be completely withdrawn from a natural gas storage facility. 
The U.S. natural gas pipeline network is a highly integrated transmission and distribution grid that can transport natural gas to and from nearly any location in the Lower 48 States. The natural gas pipeline grid comprises: ${ }^{4}$

- More than 210 natural gas pipeline systems;

- 305,000 miles of interstate and intrastate transmission pipelines;

- More than 1,400 compressor stations that maintain pressure on the natural gas pipeline network and assure continuous forward movement of supplies;

- More than 11,000 delivery points, 5,000 receipt points, and 1,400 interconnection points that provide for the transfer of natural gas throughout the United States; ${ }^{5}$

- 24 hubs or market centers;

- 400 underground natural gas storage facilities;

- 49 locations where natural gas can be imported/exported via pipelines; and

- 8 LNG import facilities and 100 LNG peaking facilities. ${ }^{6}$

4 EIA (Energy Information Administration), undated a. "About U.S. Natural Gas Pipelines - Transporting Natural Gas,” available at http://www.eia.gov/pub/oil_gas/natural_gas/analysis_publications/ngpipeline/index.html, accessed September 16, 2014.

5 A delivery point is the physical point at which the seller delivers natural gas to the buyer. A receipt point is a custody transfer point through which natural gas flows from a wellhead or other point on an upstream pipeline system into another system for transportation. An interconnect is a connection point between the transmission company and the receiving party, which may be another pipeline (interstate or intrastate), distribution company, or another customer.

6 An LNG import facility is a purpose-built port used exclusively to export or import LNG, while an LNG peaking facility stores natural gas for "peak shaving," when the LNG is vaporized and transported in gas transmission or gas distribution pipelines for periods of peak demand. 


\section{Key Hazards}

Natural gas TS\&D organizations need to manage a complex portfolio of risks. The risks can range from minor events to major incidents that could involve serious personnel injuries, cause significant environmental damage, or have substantial financial impacts. In the United States, the natural gas industry has been relatively successful in managing the risks associated with major incident risks. Such natural and man-made disasters are a major concern to the industry, but most companies understand and are able to handle disruptions to their own physical infrastructure, and the industry has in place well-established practices for handling these events. Nevertheless, the challenge remains to reduce the occurrence of such events. ${ }^{7}$ Increasing the use of natural gas in the United States to meet future demands will require the development of additional pipeline systems and the increased use of existing pipeline infrastructure.

The causes of pipeline incidents fall into several broad categories based on how the U.S. Department of Transportation (DOT) Pipeline and Hazardous Materials Safety Administration (PHMSA) collects incident data from pipeline operators. Figure 1 shows the number and percentage of significant onshore gas transmission pipeline incidents attributable to different categories of causes during 2006-2010. Only incidents involving "line pipe" are included (i.e., pipeline facilities, such as compressor stations, are not included so the focus can remain only on pipeline incidents). For gas transmission pipelines, the predominant causes of failure for line pipe are corrosion, material/weld failures, and excavation damage. ${ }^{8}$

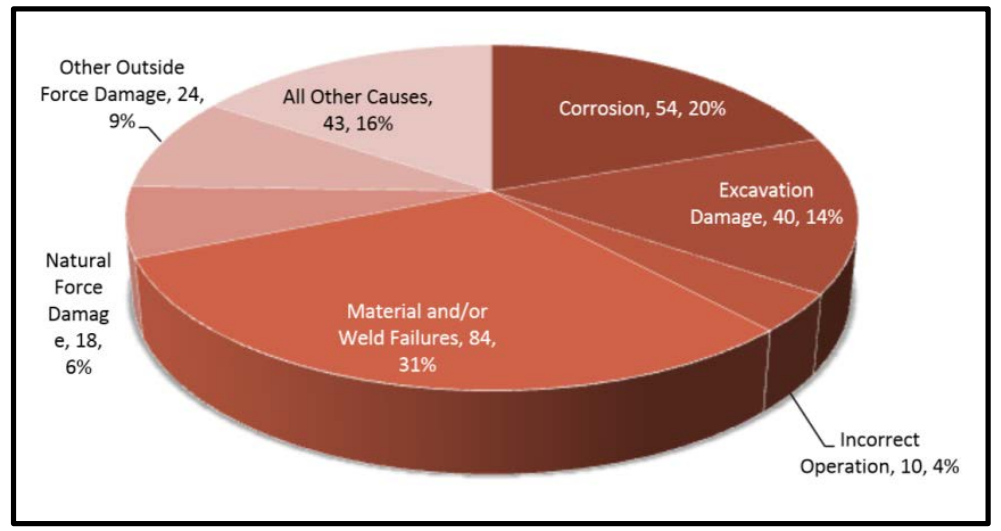

Figure 1: Significant Gas Transmission System Incidents by Cause, 2006-20109

Figure 2 shows that for U.S. distribution pipeline systems, the most significant individual categories of causes of significant incidents are excavation damage, other outside force damage, and other unspecified causes. Excavation damage often results from someone excavating without asking or without waiting for the standard 48 hours to allow the gas company to mark the location of its lines. The major contributor to the other outside force damage a vehicle not engaged in excavation. The category of all other causes represents a major fraction of significant

7 International Association of Oil and Gas Producers, 2008. Asset Integrity - The Key to Managing Major Incident Risks, available at http://www.ogp.org.uk/pubs/415.pdf, accessed September 16, 2014.

8 DOT (U.S. Department of Transportation), undated. The State of the National Pipeline Infrastructure, available at https://opsweb.phmsa.dot.gov/pipelineforum/docs/Secretarys\%20Infrastructure\%20Report_Revised\%20per\% 20PHC_103111.pdf, accessed September 16, 2014.

9 Ibid. 
incidents. This category is consists of any causes that do not fit into another category, and that includes deterioration of the pipe material. Corrosion sometimes results from excavation damage. Although it might not be severe enough to trigger a puncture or failure of the pipeline, it can create weaknesses in the pipeline that later make the pipeline even more susceptible to corrosion. $^{10}$

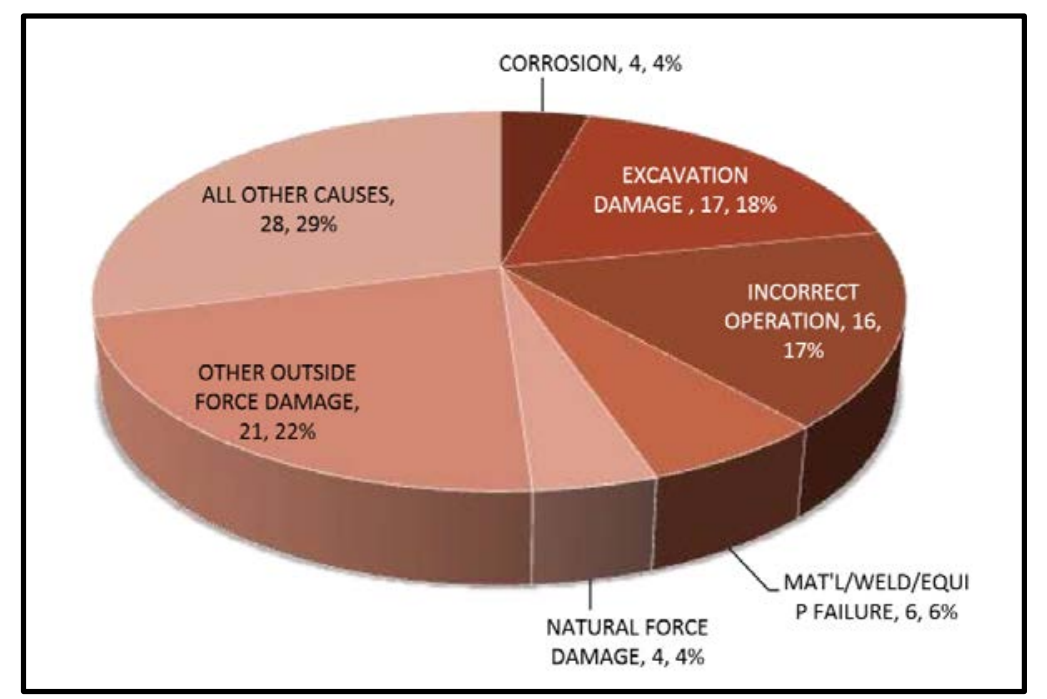

Figure 2: Significant Gas Distribution System Incidents by Cause, 2008-201011

Gas distribution pipelines have delivered gas locally for almost 200 years. PHMSA incident data have shown that in spite of the continued aging of the natural gas pipeline infrastructure, its safety performance continues to gradually improve. Pipeline incidents involving death or injury to people have dropped by more than half over the past 20 years. An older pipeline does not necessarily have a higher likelihood of leaking or rupturing than does a newer one. As materials, manufacturing techniques, joining methods, and design standards have evolved, techniques for managing the integrity of older pipelines have improved. Age can contribute to a pipeline's risk, but it has been stated that effective integrity management can counterbalance the impact of aging and construction materials. ${ }^{12}$

It is projected that natural gas consumption will grow by about 0.8\%/year from 2012 to 2040; this growth will be led by increases in natural gas use for electricity generation and in the industrial sector. Natural gas is expected to be the fossil fuel most often used to replace older coal-fired generation as it is retired. ${ }^{13}$ Natural gas emits less carbon dioxide $\left(\mathrm{CO}_{2}\right)$ than other fuel sources (e.g., fuel oil or coal), with life-cycle $\mathrm{CO}_{2}$ emissions from shale-gas-generated electricity being roughly equivalent to those from conventional

${ }^{10}$ Ibid.

${ }^{11}$ U.S. Department of Transportation (DOT), undated. The State of the National Pipeline Infrastructure, available at https://opsweb.phmsa.dot.gov/pipelineforum/docs/Secretarys\%20Infrastructure\%20Report_Revised\%20per\%20P HC_103111.pdf, accessed September 16, 2014.

12 DOT, undated. The State of the National Pipeline Infrastructure, A Preliminary Report, available at https://opsweb.phmsa.dot.gov/pipelineforum/docs/Long\%20Version\%20Preliminary\%20Report\%20on\%20Infras tructure\%20040711draftwDecadeCauseCharts.pdf, accessed September 30, 2014.

13 EIA, 2014a. Annual Energy Outlook 2014, available at http://www.eia.gov/forecasts/aeo/pdf/0383\%282014\%29.pdf, accessed October 2, 2014. 
natural gas. ${ }^{14}$ Note that the increased amount of natural gas consumed to generate electric power will lead to the displacement of coal and thus regionally offset some greenhouse gas (GHG) emissions. This scenario is in agreement with the latest Intergovernmental Panel on Climate Change (IPCC) report, which concludes that GHG emissions from energy supplies could be reduced significantly by replacing current worldwide average coal-fired power plants with modern, highly efficient, natural gas combined-cycle power plants or combined heat and power plants, provided that natural gas is available and the fugitive emissions associated with extraction and supply are low or mitigated ${ }^{15}$ However, recent studies have also shown that abundant natural gas would also tend to displace renewable energy sources, and could also lead to increased emissions due to more rapid economic growth, leading to little overall change in greenhouse gas emissions, unless measures are enacted to ensure that gas predominantly replaces more carbon-intensive energy sources. ${ }^{16}$

\section{$2.1 \quad$ Natural Hazards}

The Energy Sector has long prepared for all hazards, and natural disasters have been a key focus of sector efforts. ${ }^{17}$ Occurrences in nature have the potential to disrupt the natural gas TS\&D sector. Examples include storms (ice, rain), hurricanes, tornadoes, blizzards, floods, and earthquakes. Natural hazards can impact the integrity of pipelines that present risks to local communities. For example, Superstorm Sandy wreaked havoc on the natural gas pipelines on New Jersey’s barrier islands. From Bay Head to Long Beach Island, falling trees, dislodged homes, and flooding caused more than 1,600 pipeline leaks. All he leaks were brought under control, and no one was harmed, but New Jersey Natural Gas was forced to shut down service to the region, leaving 28,000 people without gas. ${ }^{18}$

Some other natural-hazard-related events that have affected the natural gas pipeline sector are listed here:

- Heavy winter storms resulted in cold-weather-related incidents in 1982 in the Middle Atlantic and Northeast States.

- Heavy storms in the autumn of 1983 resulted in major floods in Arizona and Utah.

${ }^{14}$ Heath, G.A., et al., 2014. "Harmonization of Initial Estimates of Shale Gas Life Cycle Greenhouse Gas Emissions for Electric Power Penetration,” in Proceedings of the National Academy of Sciences of the United States of America, Vol. 111, No. 31, pp. E3167-E3176, available at http://www.pnas.org/content/111/31/E3167.full, accessed April 20, 2015.

15 IPCC (Intergovernmental Panel on Climate Change), 2014. "Summary for Policymakers,” in Climate Change 2014: Mitigation of Climate Change. Contribution of Working Group III to the Fifth Assessment Report of the Intergovernmental Panel on Climate Change (Edenhofer, O., et al. (eds.). Cambridge University Press, Cambridge, United Kingdom, and New York, N.Y., available at http://mitigation2014.org/report/summary-for-policy-makers, accessed April 20, 2015.

16 McJeon H, J Edmonds, N Bauer, L Clarke, B Fisher, BP Flannery, J Hilaire, V Krey, G Marangoni, R Mi, K Riahi, H Rogner, and M Tavoni. 2014. "Limited Impact on Decadal-Scale Climate Change from Increased Use of Natural Gas." Nature, October 2014.

17 DOE and DHS, 2010. Energy Sector-Specific Plan - An Annex to the National Infrastructure Protection Plan, available at http://www.dhs.gov/xlibrary/assets/nipp-ssp-energy-2010.pdf, accessed September 16, 2014.

18 Pro Publica Inc., 2013. “Pipelines Explained: How Safe Are America’s 2.5 Million Miles of Pipelines?” available at http://www.propublica.org/article/pipelines-explained-how-safe-are-americas-2.5-million-miles-of-pipelines, accessed September 16, 2014. 
- A once-in-a-century freeze hit California in December 1990. After nearly two weeks of temperatures that dropped to critical levels in many districts, this went down in history as the worst freeze on record for the state.

- The 1994 Northridge Earthquake (M 6.7) in California resulted in an increased number of natural-hazard-related pipeline incidents.

- Hurricanes Rita and Katrina in 2005 resulted in substantial damage in the U.S. southern coastal areas.

Although natural hazards are cited as the cause in fewer than 10 percent of pipeline incidents, the failure of a large-diameter, high-pressure natural gas or hazardous liquid transmission pipeline during an earthquake or hurricane can significantly complicate a community's ability to respond to and recover from the event. ${ }^{19}$

A 2014 analysis of U.S. pipeline incidents induced by natural hazards indicates that such hazards are a non-negligible threat to pipelines transporting hazardous materials. It shows that geological hazards triggered 37\% of the onshore pipeline incidents; meteorological (29\%), hydrological (14\%), and climatic (14\%) hazards followed in importance. Landslides were the main geological hazard, causing $46 \%$ of the geological incidents, whereas earthquakes represented only $9 \%$ of the incidents within the category. Among meteorological hazards, lightning was the major one, causing $36 \%$ of the incidents. Floods were found to be responsible for $86 \%$ of the hydrologicalhazard-related pipeline incidents. Finally, cold-weather-related hazards (frost, low temperatures) represented $94 \%$ of the pipeline incidents caused by adverse climatic conditions. This information is shown in Figure 3 below. ${ }^{20}$

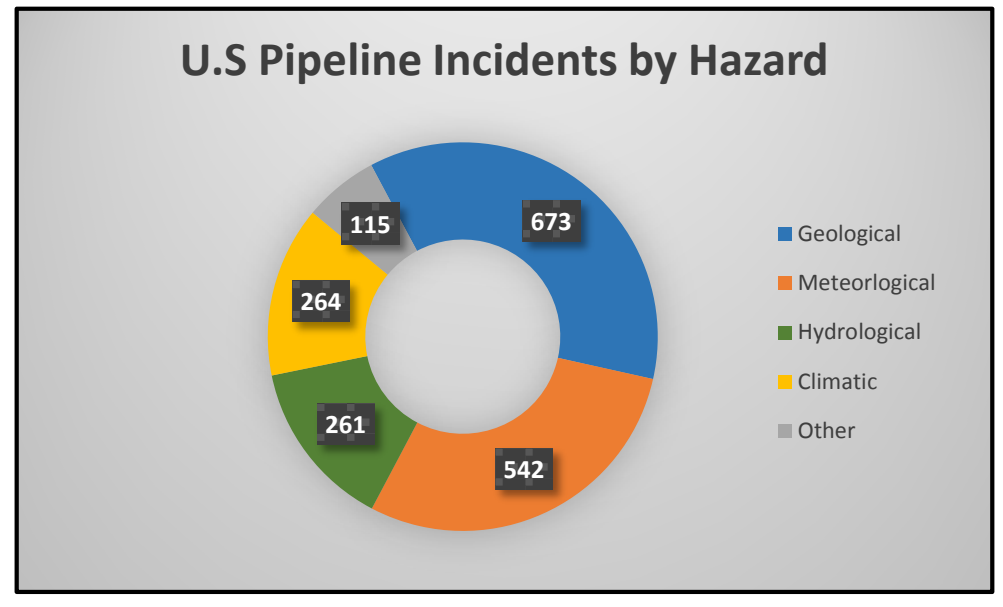

Figure 3: U.S. Pipeline Incidents by Hazard, 1982-2012

19 PHMSA (Pipeline and Hazardous Materials Safety Administration), 2011. "Hazard Mitigation Planning for Pipelines,” available at http://primis.phmsa.dot.gov/comm/pipa/pipa_hazard_mitigation.htm, accessed September 16, 2014.

${ }^{20}$ Girgin, S., and E. Krausmann, 2014. Analysis of Pipeline Accidents Induced by Natural Hazards: Final Report, available at http://www.researchgate.net/publication/259849584_Analysis_of_pipeline_accidents_induced_by nnatural_hazards_Final_Report, accessed September 16, 2014. 


\subsection{Manmade Hazards}

The category of man-made hazards, like natural hazards, is broad. These hazards can be either intentional or accidental. Acts of terrorism and mass violence are intended to do harm, while pipeline breaks can occur by accident.

Many natural-gas-related incidents result from damage to buried pipelines that occurs during excavation activities. Known as "third-party damage," this type of excavation incident is one of the leading causes of pipeline damage in the industry each year. Typically, most "serious incidents" reported to PHMSA are caused by third-party excavation incidents rather than pipeline malfunctions or deterioration. ${ }^{21}$ Over the past 20 years (1994-2014), third-party damage was the primary cause of serious incidents on natural gas pipelines, accounting for roughly 33 percent (925 out of 2,814) of all serious incidents on transmission pipelines ${ }^{22}$ and 51 percent $(2,171$ out of 4,261$)$ of such incidents on distribution pipelines. ${ }^{23,}{ }^{24}$ Since 2002, all the fatalities related to natural gas transmission incidents that occurred were excavation-related and happened to either a pipeline employee or excavation contractor. Figure 4 displays PHMSA data on serious incidents due to third-party damage that occurred on natural gas transmission pipelines during the last 20 years. ${ }^{25}$ It shows that the majority of property damage to natural gas transmission pipelines over the 1994-2014 period were associated with third-party damage.

The sheer size of the U.S. natural gas pipeline system makes it vulnerable to numerous intentional threats, including explosive-, ballistic-, sabotage-, and vandalism-related threats. Explosive threats can involve improvised explosive devices (IEDs) or vehicle-borne IEDs (VBIEDs). The proximity of pipelines to the vehicular infrastructure (roads, parking areas, and bridges) contributes to their vulnerability; this infrastructure allows easy access for IEDs and VBIEDs. General hardening of the pipeline infrastructure against these threats would be exorbitantly expensive; the size of the infrastructure is simply too great. The vast size of the pipeline system has also prevented broad surveillance of it, due to the cost of security personnel and instrumentation needed to monitor such a large area. ${ }^{26}$

${ }^{21}$ PHMSA, 2014a. A Study on the Impact of Excavation Damage on Pipeline Safety, available at http://phmsa.dot.gov/pv_obj_cache/pv_obj_id_C0FC8CF4D3B30B504A395E7A6F566C71E318C600/filename/ S10_140728_011_F reduced.pdf, accessed April 21, 2014.

22 There was a total of 925 third-party-related incidents from 1984 to 2014, out of a total of 2,814 events that affected the U.S. natural gas transmission pipeline network.

${ }^{23}$ There was a total of 2,171 third-party-related incidents from 1984 to 2013, out of a total of 4,261 events that affected the U.S. natural gas distribution pipeline network.

${ }^{24}$ American Gas Association (AGA), 2014. "Pipeline Safety, An Overview," available at http://www.aga.org/ourissues/safety/pipleinesafety/Pages/default.aspx, accessed October 13, 2014.

25 PHMSA, 2014b. Pipeline Incidents by System Type: Serious, available at https://hip.phmsa.dot.gov/analyticsSOAP/saw.dll?Portalpages\&NQUser=PDM_WEB_USER\&NQPassword=Pub lic_Web_User1\&PortalPath=\%2Fshared\%2FPDM\%20Public\%20Website\%2F_portal\%2FSC\%20Incident\%20Tr end\&Page=Serious, accessed October 13, 2014.

${ }^{26}$ DHS, 2005. Characteristics and Common Vulnerabilities Infrastructure Category: Petroleum Pipelines, April 22, Washington D.C., available at http://www.dhs.gov/index.shtm, accessed October 13, 2014. 


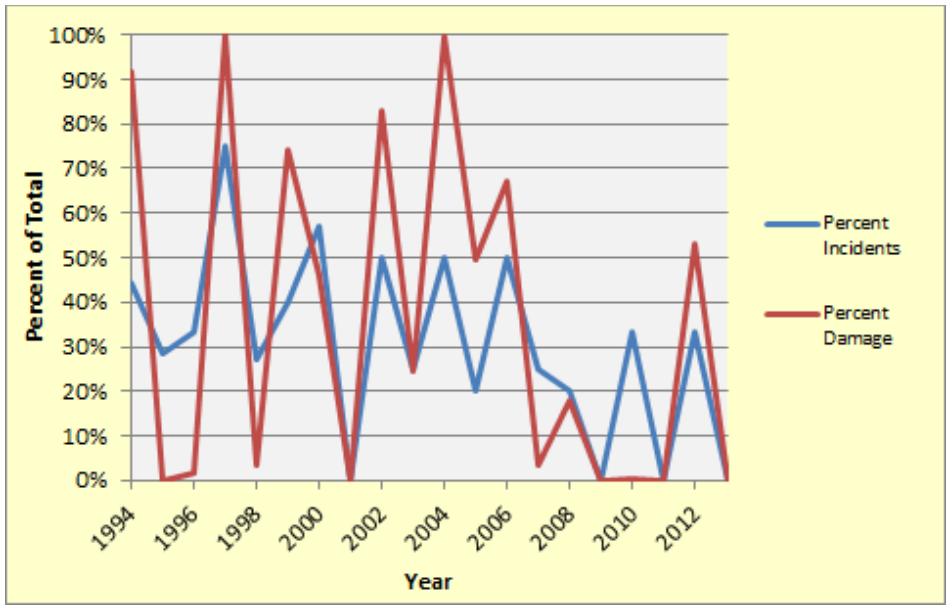

Figure 4: Percent of PHMSA Serious Incidents Due to Third-Party Damage to Natural Gas Transmission Pipelines ${ }^{27}$

Natural gas pipelines have been a target of terrorists both within and outside the United States. In November 2007, a U.S. citizen was convicted of trying to conspire with Al Qaeda to attack a major natural gas pipeline in the Eastern United States. ${ }^{28}$ On August 15, 2012, a contractor unearthed a pipe bomb near a pipeline that was under construction for the National Fuel Supply Corporation in Washington County, Pennsylvania. The pipe bomb was detonated by the Allegheny County bomb squad without causing injury or death to any people working in the area. ${ }^{29}$ An example of a pipeline bombing outside the United States involved natural gas pipelines in British Columbia, Canada, which were bombed six times between October 2008 and July 2009. ${ }^{30}$ However, the number of vandalism/sabotage incidents affecting natural gas transmission pipelines on an annual basis was generally low (typically one incident per year, see Figure 5), and most transmission pipeline incidents were caused by bullet holes or punctures (that were not due to explosives). ${ }^{31}$

27 Ibid.

${ }^{28}$ Carafano, J.J., et al., 2012. "Fifty Terror Plots Foiled since 9/11: The Homegrown Threat and the Long War on Terrorism,” The Heritage Foundation, April 25, available at http://www.heritage.org/research/reports/2012/04/ fifty-terror-plots-foiled-since-9-11-the-homegrown-threat-and-the-long-war-on-terrorism, accessed October 13, 2014.

29 Detrow, S., 2012. "Pipe Bomb Found near Allegheny County Pipeline,” State Impact Pennsylvania, August 15, available at http://stateimpact.npr.org/pennsylvania/2012/08/15/pipe-bomb-found-near-allegheny-countypipeline/, accessed October 13, 2014.

30 CBC News, 2010. “Convicted Bomber Ludwig Arrested in B.C. Pipeline Blasts,” available at http://www.cbc.ca/news/canada/british-columbia/convicted-bomber-ludwig-arrested-in-b-c-pipeline-blasts1.906851, January 8, accessed October 13, 2014.

31 PHMSA, 2014b. Pipeline Incidents by System Type: Serious, available at https:/hip.phmsa.dot.gov/analyticsSOAP/saw.dll?Portalpages\&NQUser=PDM_WEB_USER\&NQPassword=Pub lic_Web_User1\&PortalPath=\%2Fshared\%2FPDM\%20Public\%20Website\%2F_portal\%2FSC\%20Incident\%20Tr end\&Page=Serious, accessed October 13, 2014. 


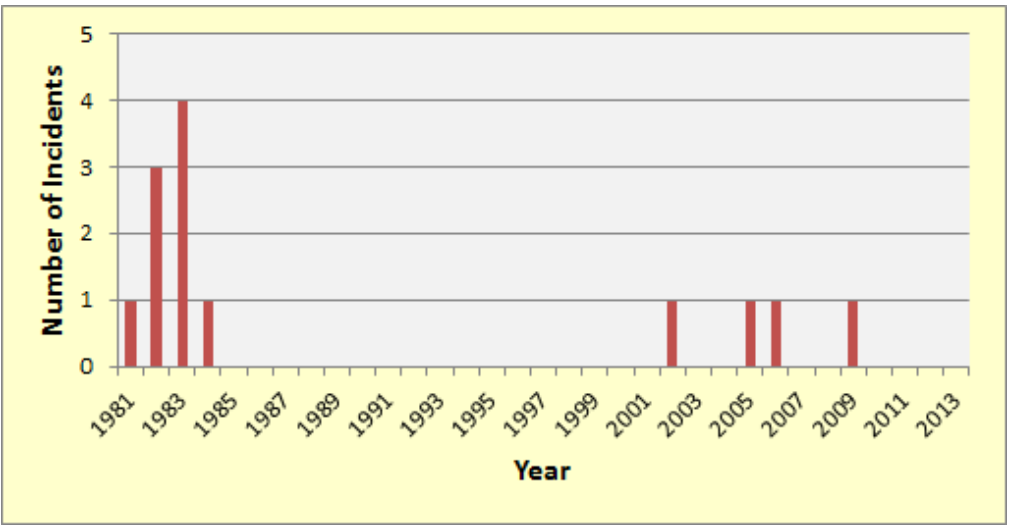

Figure 5: PHMSA Data on the Number of Natural Gas Transmission Pipeline Vandalism/Sabotage Incidents by Year in the United States ${ }^{32}$

\subsubsection{Cyber Attack}

The vast U.S. network of natural gas pipelines is vulnerable to cyber attacks. In particular, cyber infiltration of supervisory control and data acquisition (SCADA) ${ }^{33}$ systems could allow successful hackers to disrupt pipeline service and cause spills, explosions, or fires—all from remote locations. ${ }^{34}$

In 2012, the Industrial Control Systems Cyber Emergency Response Team (ICS-CERT) issued a series of warnings about cyber attacks that had targeted pipeline companies in the natural gas industry. ${ }^{35}$ Later, it was reported that ICS-CERT claimed that on February 22, 2013, it received a report from a natural gas compressor station owner about an increase in brute force attempts to access its process control network. It was later determined that a number of other natural gas pipelines were subject to similar cyber attacks. Fortunately, none of the brute force attempts were successful, and the attacks stopped after March 8, 2013. ${ }^{36}$

It was then revealed that from December 2011 through June 2012, cyber spies targeted 23 gas pipeline companies with emails crafted to deceive key personnel into clicking on malicious links or file attachments that let the attackers slip into company networks. Sensitive files that could give a cyber intruder the ability to control or alter the operation of the pipelines were stolen; the files included usernames, passwords, personnel lists, system manuals, and pipeline control system access credentials. According to a source familiar with the DHS investigation, hackers

${ }^{32}$ Ibid

${ }^{33}$ SCADA systems are software-based industrial control systems used to monitor and control many aspects of network operation for railways, utility power grids, water and sewer systems, and pipeline networks.

${ }^{34}$ CRS (Congressional Research Service), 2012. Pipeline Cybersecurity: Federal Policy, available at http://fas.org/sgp/crs/homesec/R42660.pdf, accessed October 13, 2014.

35 Ragan, S., 2012. "Report: DHS Requested Gas Pipeline Companies to Let Attackers Lurk inside Networks," Security Week, May 8, available at http://www.securityweek.com/report-dhs-requested-gas-pipeline-companieslet-attackers-lurk-inside-networks, accessed October 13, 2014.

${ }^{36}$ Lennon, M., 2013. “Cyber Attacks Targeted Key Components of Natural Gas Pipeline Systems,” Security Week, July 1, available at http://www.securityweek.com/cyber-attacks-targeted-key-components-natural-gas-pipelinesystems, accessed October 13, 2014. 
could use the data to directly reset computer-controlled pipeline systems, sabotaging them by allowing extreme pipeline pressures or unsafe valve settings that could result in explosions or other critical failures. ${ }^{37}$

The increased vulnerability of pipeline SCADA systems (due to their transition from closed, isolated networks to open, Internet protocol-based networks), taken together with the emergence of SCADA-specific malicious software and the recent occurrence of cyber attacks, suggest that cybersecurity threats to pipelines have been increasing. Depending on the configuration of a particular pipeline system, cyber attacks could potentially disrupt pipeline service, damage pipeline equipment (e.g., due to excessive pressure), or cause a hazardous release of pipeline commodities into the environment. Even if a hacker did not plan to damage or disrupt a pipeline system, by gaining access to or control of the SCADA system, the intruder could unintentionally cause serious harm.

37 Clayton, M., 2013. “Exclusive: Cyberattack Leaves Natural Gas Pipelines Vulnerable to Sabotage,” The Christian Science Monitor, February 27, available at http://www.csmonitor.com/Environment/2013/0227/Exclusive-Cyberattack-leaves-naturalgas-pipelines-vulnerable-to-sabotage, accessed October 13, 2014. 


\section{Vulnerabilities}

Vulnerabilities are the characteristics of an asset, system, or network's design, location, security posture, process, or operation that render it susceptible to destruction, incapacitation, or exploitation by mechanical failures, natural hazards, terrorist attacks, or other malicious acts. Vulnerability assessments identify areas of weakness that could result in consequences of concern, taking into account intrinsic structural weaknesses, protective measures, resilience, and redundancies. ${ }^{38}$

The physical vulnerabilities of the natural gas TS\&D sector to various threats vary depending on the infrastructure component. The natural gas TS\&D sector contains several components that could be ranked "high" in terms of the degree of vulnerability, meaning the level to which that particular component is susceptible to damage and failure from a given hazard. These highranking components include natural gas transmission pipelines, compressor stations (used to cause the commodity to flow through pipelines), storage, and distribution. Disruptions of these components could result in significant infrastructure outages.

Table 1, a vulnerability matrix, reflects the judgment of the authors of this report, based on relevant literature and 37 studies conducted by members of the natural gas team. (Appendix A has a list of natural gas studies, and Appendix B has a more a more detailed description of "vulnerability" and a key to the numerical scale.)

Table 1: Hazard Risksa for the Natural Gas Infrastructure

\begin{tabular}{|c|c|c|c|c|c|c|c|c|c|c|c|}
\hline $\begin{array}{l}\text { Infrastructure } \\
\text { Component }\end{array}$ & 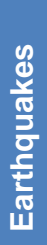 & $\frac{\sqrt{1}}{3}$ & 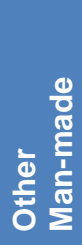 & $\begin{array}{l}\frac{\mathfrak{e}}{0} \\
\frac{0}{3} \\
\frac{0}{0}\end{array}$ & 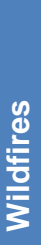 & $\begin{array}{l}\text { 을 } \\
\text { 응 } \\
\frac{8}{4}\end{array}$ & 올 & $\frac{\text { d }}{\frac{0}{3}}$ & 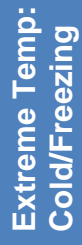 & 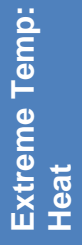 & 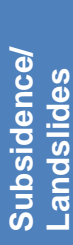 \\
\hline $\begin{array}{l}\text { Natural Gas Well } \\
\text { Production }\end{array}$ & 1 & 2 & 4 & 2 & 3 & 3 & 2 & 2 & 4 & 1 & 2 \\
\hline $\begin{array}{l}\text { Natural Gas } \\
\text { Transmission }\end{array}$ & 4 & 3 & 2 & 1 & 2 & 2 & 1 & 1 & 2 & 1 & 5 \\
\hline $\begin{array}{l}\text { Natural Gas } \\
\text { Compressor Stations }\end{array}$ & 2 & 3 & 4 & 1 & 2 & 1 & 2 & 1 & 2 & 1 & 4 \\
\hline $\begin{array}{l}\text { Natural Gas } \\
\text { Distribution Pipelines }\end{array}$ & 4 & 1 & 2 & 1 & 2 & 3 & 1 & 1 & 2 & 1 & 5 \\
\hline $\begin{array}{l}\text { Natural Gas } \\
\text { Underground Storage }\end{array}$ & 1 & 2 & 2 & 1 & 2 & 1 & 1 & 1 & 1 & 1 & 1 \\
\hline
\end{tabular}

a A value of 1 indicates low or minor vulnerability, while a value of 5 denotes high vulnerability.

38 DOE and DHS, 2010. Energy Sector-Specific Plan - An Annex to the National Infrastructure Protection Plan, available at http://www.dhs.gov/xlibrary/assets/nipp-ssp-energy-2010.pdf, accessed September 16, 2014. 
Key vulnerabilities include earthquakes and subsidence/landslides $(4,5)$, which agrees with a study by Girgin and Krausmann (2014) ${ }^{39}$ that showed that landslides are the main geological hazard, followed by earthquakes. Because of the long, linear nature of pipeline corridors, they often cross areas that are highly susceptible to landslides. Also, almost every pipeline that traverses areas in mountainous terrain has some vulnerability to landslide hazards. ${ }^{40}$ In addition, multiple national laboratory studies show that gas transmission and distribution pipeline networks could be severely affected by a number of potential earthquake scenarios (see Appendix A). These studies specifically indicate that transmission and distribution pipelines located near fault lines would be the components of the natural gas infrastructure most affected by soil liquefaction and landslides resulting from earthquakes.

High-pressure natural gas pipelines fail when subjected to permanent ground deformation due to seismically induced movement, and if an ignition source is available, they can explode. For example, gas leaked from a failed 22-inch natural gas pipeline as a result of the 1994 Northridge earthquake. It was ignited by the ignition system on a nearby truck and burned nearby houses. ${ }^{41}$ Gas compressor stations generally have performed well under earthquake conditions because they are typically conservatively designed and built. Damage to compressor stations generally occurs at unanchored mechanical or electrical components, with limited damage to gas seals. ${ }^{42}$

Historic events indicate that extremely cold temperatures most adversely affect natural gas well production. For example, in early February 2011, weather much colder than normal in the Southwest United States curtailed more than 7 billion cubic feet/day (Bcf/d) of natural gas production due to well freeze-offs. ${ }^{43}$

Table 1 also indicates that natural gas underground storage is not severely affected by natural hazards, even earthquakes. Available literature states that because of the depth of underground storage and the design of the systems connecting the storage to the surface, a storage facility is well protected from accidents or malicious acts and is insensitive to natural events such as earthquakes. If an incident occurs at the surface, the product that is stored underground can easily be isolated, and there is no risk of fire or explosion due to the absence of oxygen in the system. $^{44}$

${ }^{39}$ Girgin, S., and E. Krausmann, 2014. Analysis of Pipeline Accidents Induced by Natural Hazards: Final Report, available at http://www.researchgate.net/publication/259849584_Analysis of pipeline accidents induced by_natural_hazards_Final_Report, accessed September 16, 2014.

${ }^{40}$ USGS (U.S. Geological Survey), 2008. Landslide and Land Subsidence Hazards to Pipelines, available at http://pubs.usgs.gov/of/2008/1164/pdf/OF08-1164_508.pdf, accessed September 16, 2014.

${ }^{41}$ Ballantyne, D., 2008. Oil and Gas Pipelines, May, available at http://www.colorado.edu/hazards/ shakeout/pipelines.pdf, accessed October 14, 2014.

42 FEMA (Federal Emergency Management Agency), 2003. Multi-hazard Loss Estimation Methodology, Earthquake Model, HAZUS ${ }^{\circledR} M H$ MR4 Technical Manual, available at http://www.fema.gov/media-librarydata/20130726-1716-25045-6422/ hazus_mr4_earthquake_tech_manual.pdf, accessed October 14, 2014.

${ }^{43}$ EIA, 2011. "Winter Supply Disruptions from Well Freeze-offs Can Rival Effects of Summer Storms,” available at http://www.eia.gov/todayinenergy/detail.cfm?id=3390, accessed September 16, 2014.

${ }^{44}$ GeoStock Us, LLC. 2009. "Natural Gas Storage Primer," available at http://www.geostockus.com/what-wedo/natural-gas-storage-primer, accessed September 16, 2014. 
Pipelines, which typically run both above and below the ground, represent a highly dispersed element of the energy system that (like electric transmission lines) is difficult to protect. Since most pipelines are located underground and are generally difficult to locate accurately, the impact of a man-made attack is minimized. On the other hand, the vulnerability of above-ground compressor stations to man-made attacks is more significant.

The low vulnerability of natural gas distribution pipelines to cyber attacks is based on a lack of evidence that America's natural gas pipelines have been sabotaged. However, a government report does say that in a cyber-attack against 23 natural gas pipeline operators, crucial information was stolen that could compromise security. ${ }^{45}$ Also, a number of computer viruses affecting the pipeline sector have been identified in the last few years, but they appear to be general information stealers and to not directly target SCADA systems. ${ }^{46}$

Table 1 also indicates that pipelines are not highly vulnerable to natural hazard threats such as drought, wildfire, snow/ice, etc. The majority of the natural gas pipelines in the United States (in Alaska) are located aboveground in permafrost conditions. Only a few miles of the Nuiqsut Natural Gas Pipeline in northwestern Alaska is located underground in nearly continuous permafrost conditions. ${ }^{47}$ The majority of the natural gas pipelines in permafrost conditions (approximately 110 miles of the 120-mile pipeline) (i.e., their aboveground sections) are situated on vertical support member. Climate change could cause aboveground pipelines in permafrost to slouch as the ground recedes in a process called subsidence. If pronounced enough, subsidence can warp steel pipelines until they break. Drought is considered to have only a minimal impact because even though raw water is used in natural gas processing for steam production and cooling, processing is not considered to be a part of the TS\&D sector. High winds from hurricanes and other storms can damage aboveground infrastructure, such as compressor stations and metering stations (see Table 1), but belowground infrastructure is not likely to be affected. LNG import terminals are designed to withstand hurricane winds and storm surges. They generally shut down before a hurricane makes landfall and then restart when commercial power becomes available. ${ }^{48}$

Storm surges can affect any low-pressure cast iron ( $0.25 \mathrm{lb} / \mathrm{in}^{2}{ }^{2}$ gauge or psig) distribution systems on the U.S. East Coast by introducing water during flooding events. These events can

45 The Christian Science Monitor, 2013. “Exclusive: Cyberattack Leaves Natural Gas Pipelines Vulnerable to Sabotage,” available at http://www.csmonitor.com/Environment/2013/0227/Exclusive-Cyberattack-leavesnatural-gas-pipelines-vulnerable-to-sabotage, accessed September 16, 2014.

46 Pipeline \& Gas Journal, 2012. "Next Generation Cyber Attacks Target Oil and Gas SCADA,” available at http://pipelineandgasjournal.com/next-generation-cyber-attacks-target-oil-and-gas-scada?page=show, accessed September 16, 2014.

47 Alaska Department of Natural Resources , 2013. 2013 Annual Report State Pipeline Coordinator's Office, available at http://dnr.alaska.gov/commis/pco/documents/2013\%20annual\%20report/ SPCO 2013_AR FINAL.pdf, accessed October 27, 2014.

48 DOE, 2009. Comparing the Impacts of the 2005 and 2008 Hurricanes on U.S. Energy Infrastructure, February, available at http://energy.gov/sites/prod/files/Comparing\%20the\%20Energy\%20Infrastructure\%20Impacts\%20 of\%20the\%202005\%20and\%202008\%20Hurricanes\%20-\%20February\%202009.pdf, accessed October 14, 2014. 
also cause corrosive damage to such pipelines. ${ }^{49}$ However, most distribution systems use plastic piping and thus avoid this problem. Old cast-iron systems are being replaced, but this process could be years from completion. Overall, with regard to pipeline transportation, natural gas is much less affected by flooding than are other petroleum products, which rely more on surface infrastructure. Finally, control rooms, pump stations, and other key infrastructure are typically located away from historically observed storm surge (and flood) zones and are thus not vulnerable. Hurricane impacts to offshore gas production wells are not considered part of the TS\&D sector for this report.

49 DOE, 2013. Comparing the Impacts of Northeast Hurricanes on Energy Infrastructure, April, available at http://energy.gov/sites/prod/files/2013/04/f0/Northeast\%20Storm\%20Comparison_FINAL_041513c.pdf, accessed October 14, 2014. 


\section{Regional Aspects and Impacts}

The impacts of the natural gas infrastructure in the U.S. vary by region. There are six different regions of pipeline system operation in the country: the Northeast, Midwest, Southeast, Southwest, Central, and Western regions. An overview of each region is provided below.

Twenty interstate natural gas pipeline systems operate within the Northeast Region (Connecticut, Delaware, Massachusetts, Maine, New Hampshire, New Jersey, New York, Pennsylvania, Rhode Island, Virginia, and West Virginia). These interstate pipelines deliver natural gas to several intrastate natural gas pipelines and at least 50 local distribution companies in the region. In addition, they also serve large industrial concerns and, increasingly, natural-gas-fired electric power generation facilities.

Twenty-six interstate, and at least eight intrastate, natural gas pipeline companies operate within the Midwest Region (Illinois, Indiana, Michigan, Minnesota, Ohio, and Wisconsin). The principal sources of natural gas for the region are production areas in the Southwest, although Canadian natural gas pipelines now account for about one-fourth of natural gas pipeline capacity entering the region. Regional natural gas production, principally from Ohio and Michigan, accounts for a little more than 8 percent of the gas consumed in the region.

Twenty-three interstate, and at least eight intrastate, natural gas pipeline companies operate within the Southeast Region (Alabama, Florida, Georgia, Kentucky, Mississippi, North Carolina, South Carolina, and Tennessee). Fifteen of the twenty-three interstate natural gas pipelines originate in the Southwest region and receive most of their supplies from the Gulf of Mexico or from the States of Texas and/or Louisiana. Of those fifteen, nine natural gas pipelines actually flow all or a substantial portion, of their deliveries beyond the region, to points within the Northeast or Midwest Regions. The remaining natural gas pipeline companies, except for Columbia Gas Transmission Company (which is primarily a Northeast regional pipeline that also supplies a small territory in northern North Carolina) serve the needs of natural gas shippers and customers within the Southeast Region itself.

Most of the major onshore interstate natural gas pipeline companies operating in the Southwest Region (Arkansas, Louisiana, New Mexico, Oklahoma, and Texas) are primarily exporters of the region's natural gas production to other parts of the country and Mexico. An extensive Gulf of Mexico and intrastate natural gas pipeline network is the main conduit for deliveries within the region. More than 56,000 miles of natural gas pipeline on more than 66 intrastate natural gas pipeline systems (including offshore-to-onshore and offshore Gulf of Mexico pipelines) deliver natural gas to the Southwest Region's local natural gas distribution companies and municipalities and to the many large industrial and electric power facilities located in the region.

Twenty-two interstate, and at least thirteen intrastate, natural gas pipeline companies operate in the Central Region (Colorado, Iowa, Kansas, Missouri, Montana, Nebraska, North Dakota, South Dakota, Utah, and Wyoming). Twelve interstate natural gas pipeline systems enter the region from the south and east, while four enter from the north and carry Canadian supplies. The average utilization rates for the systems shipping Canadian natural gas tend to be higher than those carrying domestic supplies. The Central Region consumes about 48 percent less natural gas 
than it produces and is therefore a net exporter of natural gas. The region has several large metropolitan markets that are major destinations on the regional interstate natural gas pipeline network.

Ten interstate, and nine intrastate, natural gas pipeline companies provide transportation services to and within the West Region (Arizona, California, Idaho, Nevada, Oregon, and Washington) the fewest number serving any region. Slightly more than half the capacity entering the region is on natural gas pipeline systems that carry natural gas from the Rocky Mountain area and the Permian and San Juan basins. These latter systems enter the region at the New Mexico-Arizona and Nevada-Utah State lines. The rest of the capacity arrives on natural gas pipelines that access Canadian natural gas at the Idaho and Washington State border crossings with British Columbia, Canada.

Table 2 shows that the largest levels of pipeline capacity exist on the natural gas pipeline systems that link the natural gas production areas of the U.S. Southwest with the other regions of the country. Sixteen of the thirty largest U.S. natural gas pipeline systems originate in the Southwest Region, with four additional ones depending heavily upon supplies from the region. The Central Region is also another net exporter of natural gas to the Midwest and West Regions. The Southeast Region receives the most natural gas from outside the region, followed by the Midwest, West, and Northeast Regions. The Northeast Region is gaining greater access to shale gas from the Marcellus Region, mostly located in West Virginia and Pennsylvania; the Marcellus Region is the largest producing shale gas basin in the United States, accounting for almost 40 percent of U.S. shale gas production. Marcellus Region production has increased dramatically over the past four years due to hydraulic fracturing; it increased from 2 Bcf/d in 2010 to a level exceeding 15 Bcf/d in July 2014. ${ }^{50}$

Table 2: Regional Net Interstate Pipeline Capacity on a State-to-State Level (2013 data, MMcf/d = million cubic feet per day)

\begin{tabular}{|c|c|c|c|c|c|c|c|c|c|c|c|}
\hline \multicolumn{2}{|c|}{ Central Region } & \multicolumn{2}{|c|}{ Midwest Region } & \multicolumn{2}{|c|}{ Northeast Region } & \multicolumn{2}{|c|}{ Southeast Region } & \multicolumn{2}{|c|}{ Southwest Region } & \multicolumn{2}{|c|}{ West Region } \\
\hline State & MMcf/d & State & MMcf/d & State & MMcf/d & State & MMcf/d & State & MMcf/d & State & MMcf/d \\
\hline Colorado & $(3,238)$ & Illinois & 2,653 & Connecticut & 1,175 & Alabama & 6,054 & Arkansas & $(1,779)$ & Arizona & 143 \\
\hline lowa & 235 & Indiana & 2,207 & Delaware & 362 & Florida & 4,930 & Louisiana & 14,749 & California & 8,788 \\
\hline Kansas & (889) & Michigan & 2,970 & Maine & 237 & Georgia & 2,500 & New Mexico & $(2,633)$ & Idaho & 316 \\
\hline Missouri & 2,666 & Minnesota & 2,031 & Maryland & 1,489 & Kentucky & 700 & Oklahoma & $(6,253)$ & Nevada & 1,281 \\
\hline Montana & 214 & Ohio & 5,183 & Massachusetts & 2,013 & Mississippi & 2,977 & Texas & $(19,538)$ & Oregon & 2,489 \\
\hline Nebraska & 1,420 & Wisconsin & 3,370 & New Hampshire & 232 & North Carolina & 1,908 & TOTAL & $(15,454)$ & Washington & 1,205 \\
\hline North Dakota & 705 & TOTAL & 18,414 & New Jersey & 1,774 & South Carolina & 647 & & & TOTAL & 14,222 \\
\hline South Dakota & 57 & & & New York & 8,385 & Tennessee & 1,081 & & & & \\
\hline Utah & (246) & & & Pennsylvania & $(2,491)$ & TOTAL & 20,797 & & & & \\
\hline Wyoming & $(7,724)$ & & & Rhode Island & 228 & & & & & & \\
\hline TOTAL & $(6,800)$ & & & Vermont & 62 & & & & & & \\
\hline & & & & Virginia & 466 & & & & & & \\
\hline & & & & West Virginia & $(1,813)$ & & & & & & \\
\hline & & & & TOTAL & 12,119 & & & & & & \\
\hline
\end{tabular}

${ }^{50}$ EIA, 2014b. "Marcellus Region production continues growth,” available at http://www.eia.gov/todayinenergy/ detail.cfm?id=17411, accessed September 16, 2014. 
Two-thirds of the Lower 48 States are almost totally dependent on the interstate pipeline system for their supplies of natural gas. The national natural gas delivery network is intricate and expansive, but most of the major transportation routes can be broadly categorized into 11 distinct corridors or flow patterns, as follows: ${ }^{51}$

- Four major routes extend from the producing areas of the Southwest,

- Four major routes enter the United States from Canada, and

- Three major routes originate in the Rocky Mountain area.

Figure 6 shows the projected changes in these inter-regional natural gas pipeline flows from 2010 to $2035 .^{52}$ It can be seen that substantial increases in flows out of the Mid-continent shale and Rocky Mountain producing basins and into California and the Midwest will continue to occur, resulting in California and the Midwest becoming more reliant on the Central Region and thus becoming more vulnerable to supply disruptions that might occur in the Central Region (from well freeze-offs, etc.).

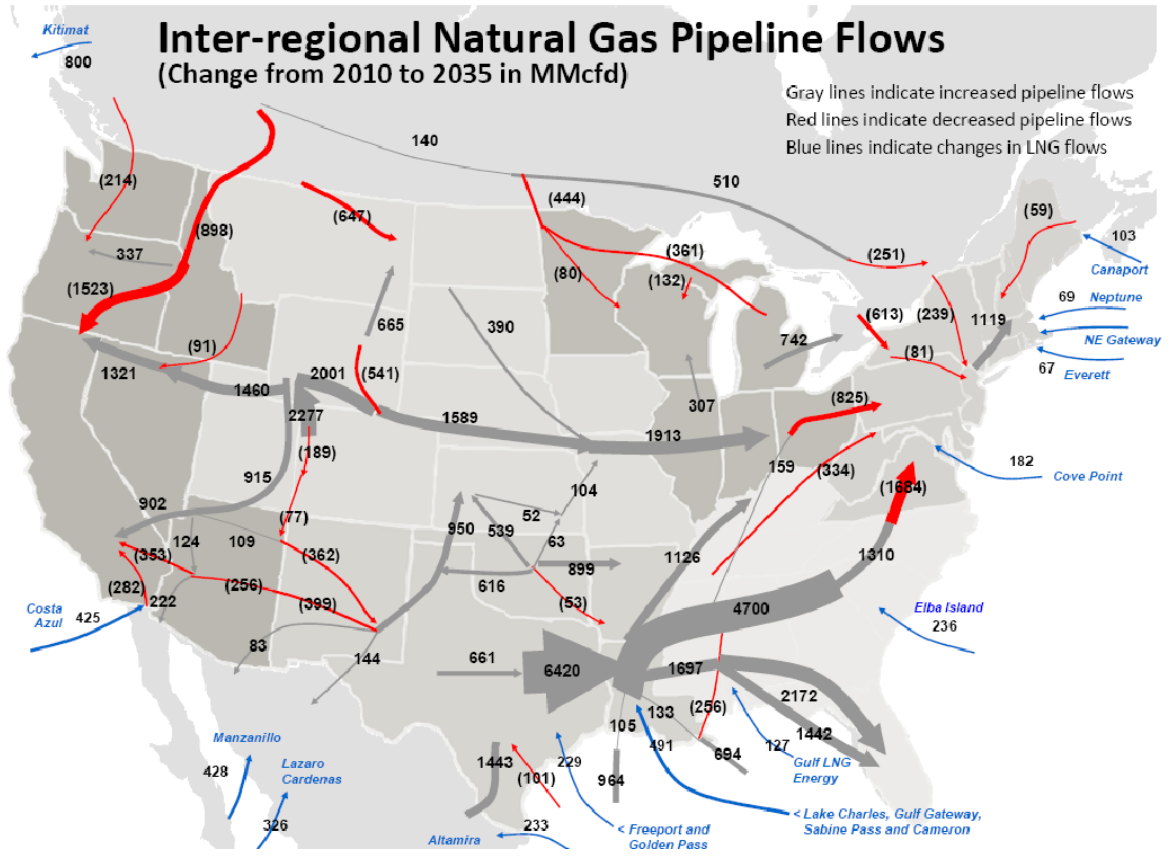

Figure 6: Inter-regional Natural Gas Pipeline Flows ${ }^{53}$

Similarly, increases in flows from the Gulf Coast to the Southeast and Lower Atlantic States due to increases in Mid-continent shale gas production would make these States vulnerable to any short- or long-term supply disruptions in Texas in the future.

51 EIA, undated b. “Major Natural Gas Transportation Corridors,” available at http://www.eia.gov/pub/oil_gas/ natural_gas/analysis_publications/ngpipeline/transcorr.html, accessed September 23, 2014.

52 ICF International, 2011. North American Midstream Infrastructure through 2035 - A Secure Energy Future, available at http://www.ingaa.org/File.aspx?id=14900, accessed September 23, 2014.

53 Ibid. 
Historically, natural gas consumed in the Northeast States was supplied from the Gulf Coast; however, Marcellus gas production growth displaces gas flows into the Northeast United States and increases the reliance of the natural gas demand in the Northeast to shale gas production in Pennsylvania and West Virginia. (Shifts within the Northeast are not depicted on this interregional flow map.)

The United States is projected to become less dependent on Canadian exports of natural gas because declining conventional production in Alberta and increasing gas consumption for oil sands development will cause flows from Western Canada to decline and also as a result of strong domestic production. This projection indicates that the United States might become independent of foreign sources of natural gas, except for regional receipts of foreign LNG. 


\section{Impacts/Severity}

Natural gas delivery disruptions occur less often than electrical outages because natural gas is distributed through underground pipelines. Severe storms, flooding, and earthquakes can expose and break pipes, however. Various sources can disrupt the natural gas system, including natural events such as flooding; accidents such as dig-ins, material and equipment failures, and procedural failures; and intentional acts such as vandalism or terrorism. When disruptions do occur, it can take weeks or even months to restore. ${ }^{54}$

The number of customers affected during a natural gas disruption is an important criterion for determining the severity of the incident. It is essential to recognize that the term "customer" refers to the individual or organization that pays the gas bill. In other words, the number of "customers" affected is different from the number of "people" affected. Interruption of an industrial plant, which is considered one customer, could affect hundreds of people, in addition to resulting in lost manufacturing production and business.

The loss of gas service to a large number of customers is a relatively rare occurrence. In the last 35 years in the Chicago Metropolitan Area, the largest number of customers losing gas service at any one time has been on the order of 4,500. (The 2011 Southwest Cold Weather Event interrupted gas service to more than 50,000 customers in New Mexico, Arizona, and Texas. ${ }^{55}$ ) When compared with the number of customers affected by electric power outages (which can be in excess of 100,000 to 1 million), the number of affected natural gas customers appears to be relatively small.

The number of customers affected, however, involves a special consideration when it comes to natural gas disruptions. Dealing with an electric power outage generally requires no visits to customer premises, but the restoration of gas service requires an initial visit to each individual customer to shut off gas valves; work to repair any equipment damage, purge the gas lines, and test for integrity; and a second visit to each individual customer to relight each appliance or manufacturing process and piece of machinery. This process is tedious and time-consuming and must be conducted with the safety of customers as the primary concern. ${ }^{56}$ A rule of thumb in the natural gas industry is that one trained technician can shut off 10 customers and relight 4 customers in an hour. ${ }^{57}$

${ }^{54}$ DOE, undated. "Homeowners: Respond to Natural Gas Disruptions,” available at http://energy.gov/oe/ community-guidelines-energy-emergencies/homeowners-respond-natural-gas-disruptions, accessed September 16, 2014.

${ }^{55}$ FERC and NERC (North American Electric Reliability Corporation), 2011. Report on Outages and Curtailments during the Southwest Cold Weather Event of February 1-5, 2011, available at http://www.nerc.com/files/ SW_Cold_Weather_Event_Final_Report.pdf, accessed September 16, 2014.

${ }^{56}$ Argonne National Laboratory, 2002. Planning for Natural Gas Disruptions, available at http://www.ipd.anl.gov/anlpubs/2003/02/45798.pdf, accessed September 16, 2014.

${ }^{57}$ Ibid. 
Table 3, a severity matrix, reflects the judgment of the authors of this report, based on the relevant literature and 37 studies conducted by multiple national laboratories. (Appendix A has a list of natural gas studies, and Appendix B has a definition of "severity" and a key to the numerical scale).

Table 3: Hazard Severitya for the Natural Gas Infrastructure

\begin{tabular}{|c|c|c|c|c|c|c|c|c|c|c|c|}
\hline $\begin{array}{l}\text { Infrastructure } \\
\text { Component }\end{array}$ & 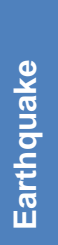 & $\frac{\vdots}{\overline{0}}$ & $\frac{\frac{d}{0}}{\frac{\pi}{d}}$ & $\begin{array}{l}\text { 흥 } \\
\text { 울 } \\
\text { 임 }\end{array}$ & $\frac{\stackrel{9}{\frac{5}{5}}}{\frac{0}{5}}$ & 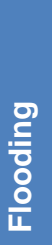 & 옳 & 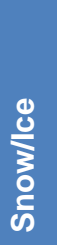 & 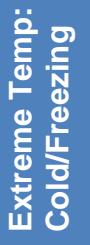 & 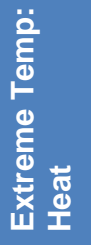 & 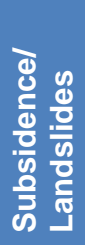 \\
\hline $\begin{array}{l}\text { Natural Gas Well } \\
\text { Production }\end{array}$ & 3 & 2 & 3 & 3 & 4 & 2 & 2 & 3 & 3 & 1 & 3 \\
\hline $\begin{array}{l}\text { Natural Gas } \\
\text { Transmission }\end{array}$ & 3 & 3 & 3 & 1 & 2 & 1 & 1 & 1 & 2 & 1 & 3 \\
\hline $\begin{array}{l}\text { Natural Gas } \\
\text { Compressor Stations }\end{array}$ & 3 & 3 & 3 & 1 & 2 & 3 & 3 & 1 & 2 & 1 & 3 \\
\hline $\begin{array}{l}\text { Natural Gas } \\
\text { Distribution Pipelines }\end{array}$ & 3 & 2 & 3 & 1 & 2 & 2 & 1 & 1 & 2 & 1 & 3 \\
\hline $\begin{array}{l}\text { Natural Gas } \\
\text { Underground Storage }\end{array}$ & 3 & 3 & 4 & 1 & 2 & 2 & 1 & 1 & 1 & 1 & 4 \\
\hline
\end{tabular}

a A value of 1 indicates low or minor severity, while a value of 5 denotes high or catastrophic severity.

No catastrophic impacts (severity value of “5”) were projected to result from the above list of potential threats, based on historical data that show that the natural gas industry is resilient to threats that it has previously encountered. The above table indicates that significant impacts are generally seen as a function of the natural gas asset and the potential threat. A major impact is projected for a natural gas underground storage facility subjected to man-made threats and subsidence/landslides. Although natural gas production is diverse, with hundreds of thousands of wells producing oil and natural gas, a wildfire that would affect a whole field would have a significant impact on natural gas deliveries. The most significantly impacted segments of the natural gas infrastructure appear to be aboveground facilities (e.g., compressor stations, natural gas well production) because of their accessibility, the expense and difficulty of replacing them, and the fact that several pipelines are concentrated at such locations. 


\section{Climate Change Implications}

Changes in temperature, precipitation, sea level, and the frequency and severity of extreme events due to human-induced climate change will likely affect how much energy is produced, delivered, and consumed in the United States, the regional distribution of these activities, and the features of energy systems that accomplish them. ${ }^{58}$ In general, the science related to indirect climate change effects, such as changes in storm patterns, is less conclusive than the scientific evidence related to direct climate change effects, such as melting snow and ice and increases in atmospheric and ocean temperatures. For example, most of the United States has experienced an increase in prolonged periods of excessively high temperatures, more heavy downpours, and rising sea levels over the past 50 years, and these trends are all expected to continue throughout the 21st century. On the other hand, both observations and climate models projections suggest that the number of Category 4 and 5 tropical storms may be increasing, and that the amount of precipitation at the center of hurricanes will increase by $20 \%$; however, the overall number of tropical cyclones may decrease slightly, and the tracks of hurricanes are also expected to change, making it difficult to make definitive conclusions about changes in risks associated with hurricane incidence and intensity. ${ }^{59}$ The potential influence of climate change on hazards to natural gas infrastructure are summarized in Table 4.

Table 4: Hazard Type Relative to Climate Effect

\begin{tabular}{|l|c|c|}
\multicolumn{1}{|c|}{ Hazard } & $\begin{array}{c}\text { Direction of Hazard } \\
\text { Change Due to Climate } \\
\text { Effect }\end{array}$ \\
\hline Earthquakes & Natural & Not applicable \\
\hline Cyber & Man-made & Not applicable \\
\hline Other Man-made & Man-made & Not applicable \\
\hline Drought & Natural & Increased in some regions \\
\hline Wildfires & Natural & Generally Increased \\
\hline Flooding & Natural & Generally Increased \\
\hline Wind & Natural & Variable \\
\hline Snow/lce & Natural & Generally Reduced \\
\hline Extreme temp: Cold/freezing & Natural & Generally Reduced \\
\hline Extreme Temp: Heat & Natural & Increased \\
\hline Subsidence: Landslides & Natural & Unknown \\
\hline
\end{tabular}

58 EPA (U.S. Environmental Protection Agency), 2013. “Climate Impacts on Energy,” available at http://www.epa.gov/climatechange/impacts-adaptation/energy.html, accessed September 16, 2014.

59 GlobalChange.gov, 2014. U.S. National Climate Assessment, Climate Change Impacts in the United States, http://nca2014.globalchange.gov. 
The following climate changes could affect pipeline operations:

- Warmer winter temperatures,

- A shorter cool season,

- Longer durations of frost-free periods,

- More freeze-thaw cycles per year (which could lead to more episodes of soil contraction and expansion),

- Warmer summer temperatures,

- Increased number of hot days and of consecutive hot days, and

- Longer summers (which could have impacts associated with heat stress and wildfires).

Warmer temperatures are leading to widespread thawing of the permafrost across high latitudes. ${ }^{60}$ Melting of permafrost can cause ground subsidence, and freeze-thaw cycles can create upward forces as ice re-forms after a thaw. There is approximately 120 miles of natural gas pipelines in continuous permafrost conditions (out of a U.S. total of 320,254 miles. ${ }^{61}$ These disturbances to soil stability can affect pipeline structural support or impinge directly on the pipelines themselves.

The statistical risk of a pipeline incident could be increased by secondary effects brought on by climatic change, such as increased flooding and drought. However, this increased risk would still be much less than the risk of an incident from other causes (such as third-party damage). ${ }^{62}$ Pipeline damage can be caused by weakened soil structure due to precipitation or inundation from storms. In addition, the pipeline roadbed can be scoured by heavy precipitation. Intense precipitation and flooding can erode soil cover and cause pipeline subsidence, leading to pipeline failure. ${ }^{63}$ Drought conditions can delay necessary pipeline inspection procedures such as hydrotesting, ${ }^{64}$ which helps maintain safety standards and the durability of a pipeline over time.

60 Ibid.

${ }^{61}$ PHMSA, , available at http://phmsa.dot.gov/portal/site/PHMSA/menuitem.6f23687cf7b00b0f22e4c6962d9c8789/?vgnextoid=78e4f5448 a359310VgnVCM1000001ecb7898RCRD\&vgnextchannel=3b6c03347e4d8210VgnVCM1000001ecb7898RCR D\&vgnextfmt=print]

${ }^{62}$ U.S. Department of State, 2014. Final Supplemental Environmental Impact Statement for the Keystone XL Project, Executive Summary, January, available at http://keystonepipeline-xl.state.gov/documents/ organization/221135.pdf, accessed October 2, 2014. [cannot open file]

63 FHWA (Federal Highway Administration), 2012c. “III(a) Precipitation - Summary,” available at www.fhwa.dot.gov/environment/climate_change/adaptation/ongoing_and_current_research/gulf_coast_study/ phase2_task2/sensitivity_matrix/matrix06.cfm, accessed September 16, 2014.

${ }^{64}$ Hydrostatic pressure testing involves pressurizing a section of pipe with water to a much higher level than that under which the pipe would ever operate with natural gas. The test validates the safe operating pressure of the pipeline. Any pipe sections that do not meet acceptable standards during the test will be replaced with new pipe that has already passed a pressure test. 
(Further information on climate change impacts on the natural gas sector are provided later in this report.)

In a warmer climate, Americans would use more electricity for air conditioning and less natural gas, oil, and wood for heating. If the nation's climate warmed by $1.8^{\circ} \mathrm{F}$, the demand for energy used for cooling would increase by about 5-20 percent, while the demand for energy used for heating would decrease by about 3-15 percent. ${ }^{65}$ Figure 7 shows how air conditioning loads have increased over time. Heating demand would decrease the most in the Northern United States. The increase in the demand for cooling is projected to be significant in areas that already experience the highest summer temperatures and areas where new air conditioning loads will be introduced. ${ }^{66,67}$ Further research and analysis to provide information on the likely spatial

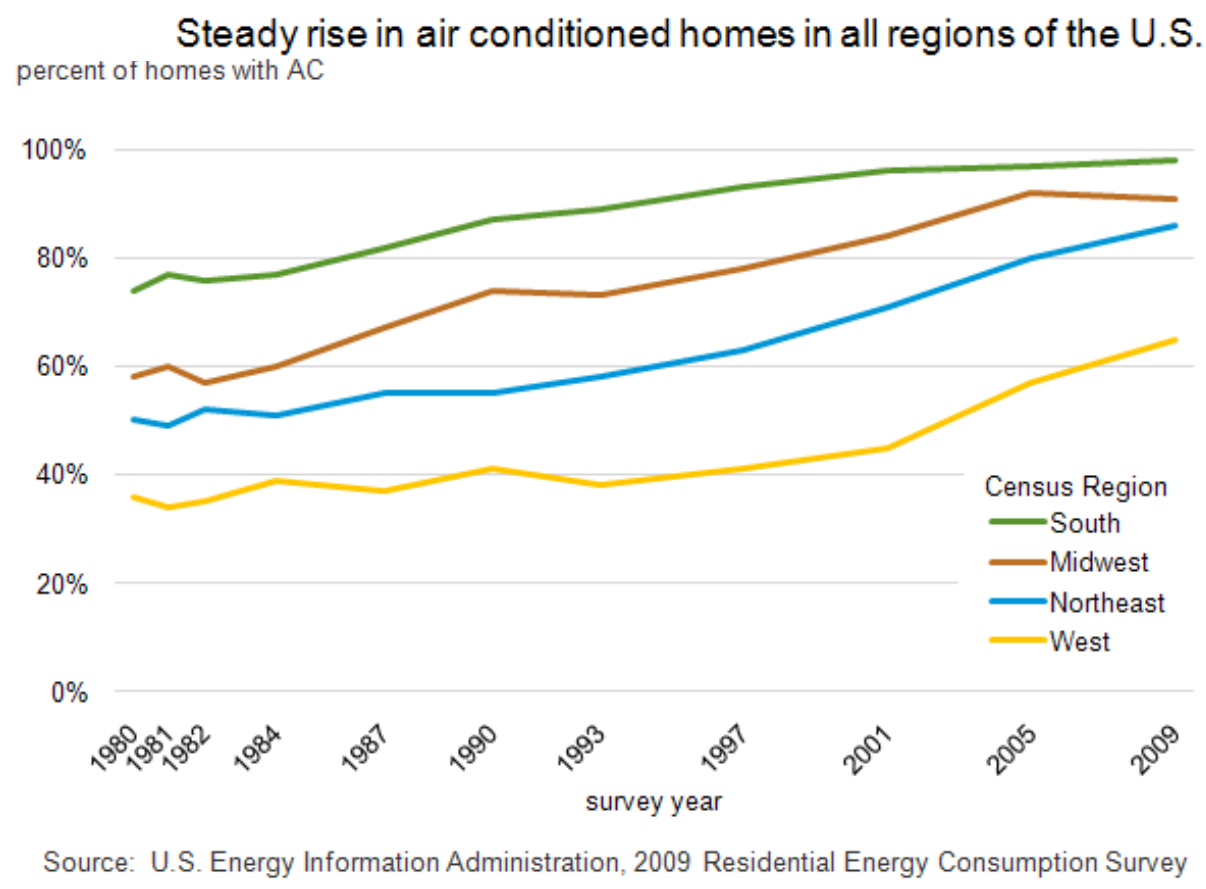

Figure 7: Steady Rise of Air-Conditioned Homes

${ }^{65}$ U.S. Department of State, 2014. Final Supplemental Environmental Impact Statement for the Keystone XL Project, Executive Summary, January, available at http://keystonepipeline-xl.state.gov/documents/ organization/221135.pdf, accessed October 2, 2014.

${ }^{66}$ Shorr, N., et al., 2009. Household Heating and Cooling Energy Use in the Northeast USA: Comparing the Effects of Climate Change with Those of Purposive Behaviors, http://www.int-res.com/articles/cr2009/39/c039p019.pdf.

${ }^{67}$ Aroonruengsawat, A., and M. Auffhammer, 2009. Impacts of Climate Change on Residential Electricity Consumption: Evidence from Billing Data, California Energy Commission, http://www.energy.ca.gov/2009publications/CEC-500-2009-018/CEC-500-2009-018-D.PDF. 
distribution of new cooling loads and on changes in cooling demand by region would be helpful going forward. ${ }^{68}$. Population growth is also expected to increase the demand for heating and cooling. However, when the effects of a warming climate are also considered along with population growth, the projected increase in energy demand for heating is about half as much. ${ }^{69}$

Energy demand is expected to shift by the end of the century. The number of "degree days" refers to the sum of the number of degrees that a day's average temperature is hotter or colder than $65^{\circ} \mathrm{F}$ over the course of a year. The number of heating degree days is expected to decrease, while the number of cooling degree days is projected to increase by 2080-2099 (Figure 8).

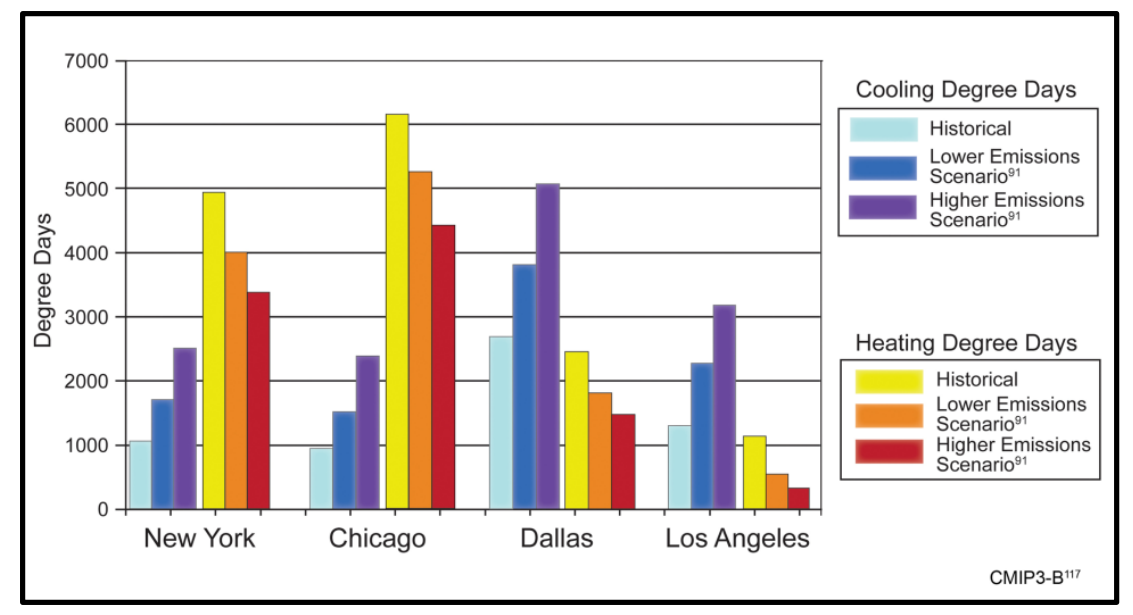

Figure 8: Projected Change in Heating-Degree Days at Four Major U.S. Urban Areas ${ }^{70}$

Figure 9 shows projected increases in the length of the frost-free season for the last three decades of the 21st century (2070-2099 compared to 1971-2000) under two emissions scenarios, one in which heat-trapping gas emissions continue to grow (A2) and one in which emissions peak in 2050 (B1). Increases in the frost-free season correspond to similar increases in the growing season. White areas are projected to experience no freezes in 2070-2099, and gray areas are projected to experience more than 10 frost-free years during the same period. ${ }^{71}$

${ }^{68}$ Franco, G., and A. Sanstad, 2006. Climate Change and Electricity Demand in California. A Report from California Climate Change Center, http://www.energy.ca.gov/2005publications/CEC-500-2005-201/CEC-5002005-201-SF.PDF.

${ }^{69}$ U.S. Department of State, 2014. Final Supplemental Environmental Impact Statement for the Keystone XL Project, Executive Summary, January, available at http://keystonepipeline-xl.state.gov/documents/ organization/221135.pdf, accessed October 2, 2014.

${ }^{70}$ USGCRP (U.S. Global Change Research Program), 2009. “Cooling and Heating Degree Days,” available at http://downloads.globalchange.gov/usimpacts/allimages/4-Energy/4-Hi\%20res/4-Energy-pg-55_bot.jpg, accessed September 16, 2014.

${ }^{71}$ USGCRP, undated. "Projected Changes in Frost-Free Season Length,” available at http://www.globalchange.gov/browse/multimedia/projected-changes-frost-free-season-length, accessed September 29, 2014. 


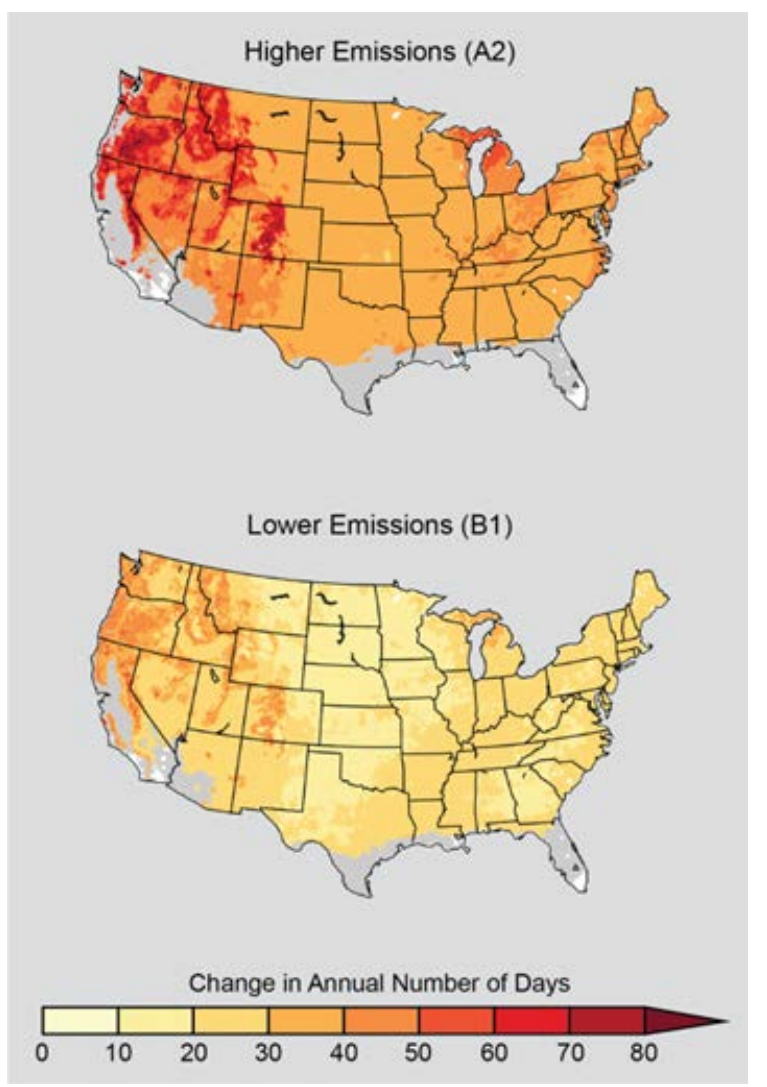

Figure 9: Projected Changes in Frost-Free Season Length

A large portion of the U.S. energy infrastructure is located in coastal areas and is thus sensitive to rises in the sea level, storm surges, and increases in the frequency and severity of wind and rain. For example, fuel ports and the generation and transmission lines that bring electricity to major urban coastal centers are at risk. Changes in the frequency and severity of storms and other extreme events might also damage energy infrastructure. Disruptions in the natural gas supply could affect electricity generation, residential and commercial heating, and industrial processes. Disruptions in electricity supply could also affect natural gas production, distribution, and use.

Flooding and intense storms can damage power lines and electricity distribution equipment. These events may also delay repair and maintenance work. Electricity outages can have serious impacts on other energy systems too. For example, oil and gas pipeline disruptions following extreme weather events are often caused by power outages rather than physical damage to the infrastructure. The Energy Information Administration indicated that a lack of electric power was one reason why dozens of natural gas processing plants shut down after hurricane landfalls in 2008. ${ }^{72}$ In addition, some pipeline compressor stations were operated on emergency backup generators since commercial electric power was unavailable for days after Hurricanes Gustav

72 EIA, undated c. Impact of the 2008 Hurricanes on the Natural Gas Industry, available at www.eia.gov/pub/oil_gas/natural_gas/feature_articles/2009/nghurricanes08/nghurricanes08.pdf, accessed September 30, 2014. 
and Ike made landfall in early September 2008. ${ }^{73}$ In the Gulf Coast, natural gas pipelines are generally below the ground and do not suffer damage from storm surges. However, pipeline damage did occur during severe Hurricanes, such as Andrew, Ivan, and Katrina.

U.S. energy facilities and systems, especially those located in coastal areas, are vulnerable to extreme weather events. Wind and storm surge damage from hurricanes already causes significant infrastructure losses on the coasts, with the Gulf Coast most affected due to the concentration of production and refining there. ${ }^{74}$ Extreme storm surge events at high tides are expected to increase, raising the risk of inundating energy facilities such as pipelines and transmission and distribution networks. This poses the risk of near-term physical disruption as well as longer-term corrosion.

Waves and storm surges generally do not damage aboveground and underground pipelines. However, damage has resulted from changes in the water table or soil stability due to a rise in the sea level, which increases the risks from wave action and storm surges to submerged or lowelevation pipelines in particular. One additional concern is the corrosion of pipes due to the intrusion saltwater into groundwater. ${ }^{75}$ Inland, torrential rains and flooding of rivers can also raise water tables and impair soil stability, and, to the extent that climate change increases the magnitude of such events, a larger area than just the coast could be affected.

Offshore pipelines, however, be damaged directly and indirectly by currents and waves generated by storms. Often, the majority of the damage to pipelines is experienced by the platforms and risers. Storms can also directly cause damage to offshore pipelines (e.g., by removing covers and spans, thereby exposing the pipeline). During Hurricanes Katrina and Rita, the majority of the offshore pipeline damage occurred at or near platform interfaces or as a result of an indirectly related force, such as platform failure, riser damage, or anchor dragging. Other damage can result due to the loss of cover and movement of pipelines that are near shore and in shallow water. ${ }^{76}$

Strong winds can uproot trees and cause other debris-related damage to gas mains, services, meters, and aboveground piping. Offices and equipment storage facilities also can experience

73 DOE, 2009. Comparing the Impacts of the 2005 and 2008 Hurricanes on U.S. Energy Infrastructure, February, available at http://energy.gov/sites/prod/files/Comparing\%20the\%20Energy\%20Infrastructure\%20Impacts\%20 of\%20the\%202005\%20and\%202008\%20Hurricanes\%20-\%20February\%202009.pdf, accessed September 30, 2014.

74 USGCRP, 2014. “2014 National Climate Assessment, Energy Supply and Use,” available at http://nca2014.globalchange.gov/report/sectors/energy, accessed September 16, 2014.

75 FHWA, 2012a. "I(a) Waves and Storm Surge - Summary,” available at https://www.fhwa.dot.gov/environment/ climate_change/adaptation/ongoing_and_current_research/gulf_coast_study/phase2_task2/sensitivity_matrix/mat rix02.cfm, accessed September 16, 2014.

76 DOE, 2009. Comparing the Impacts of the 2005 and 2008 Hurricanes on U.S. Energy Infrastructure, February, available at http://energy.gov/sites/prod/files/Comparing\%20the\%20Energy\%20Infrastructure\%20Impacts\%20 of\%20the\%202005\%20and\%202008\%20Hurricanes\%20-\%20February\%202009.pdf, accessed September 30, 2014. 
wind-related damage. Wind speeds above 60 miles per hour can damage aboveground pipeline systems. $^{77}$

Extreme precipitation or inundation from storms can damage pipelines because it has weakened the soil structure. Pipelines may be unearthed during flooding, and connections to buildings may be severed if the buildings shift. Extreme precipitation can also trigger landslides, which can disrupt pipelines. This disruption can, in turn, disrupt inspection, construction, or maintenance cycles. $^{78}$ In addition, heavy rains/floods can result in pipeline failure; DOT incident data for the years 2002-2009 indicate a total of 92 incidents in which heavy rains/floods were identified as the cause of natural gas transmission pipeline failure. ${ }^{79}$

Preventing the freezing of natural gas pipelines and systems is the primary temperature-related design consideration. Temperature regulation considerations primarily relate to managing pressure drops within the natural gas pipeline system, since this will decrease temperatures due to physical laws; most freezing problems occur when the ambient temperature is from 35 to $45^{\circ} \mathrm{F}$, because water will not freeze to a pipeline that is at this temperature but it will freeze at the point where the pressure and temperature drop in the pressure-regulating valve. It is possible that low overall system pressure due to high demand during extreme cold weather events could exacerbate this issue. ${ }^{80}$ There are still about 36,000 miles of cast-iron main gas distribution lines in the United States. Most of this is concentrated in five states: New Jersey, New York, Massachusetts, Pennsylvania, and Michigan; 80\% is concentrated in just 10 states. Smalldiameter cast-iron pipes have low beam strength and are particularly susceptible to stresses from freeze-thaw cycles. ${ }^{81}$

There is no documented relationship of any significant effect on pipelines due to increased or decreased temperatures. Soil cover and water moderate any air temperature effects, and pipelines are already designed to accommodate significant temperature variations. ${ }^{82}$

77 FHWA, 2012b. “II(a) Wind - Summary,” available at https://www.fhwa.dot.gov/environment/climate_change/adaptation/ongoing_and_current_research/gulf_coast_ study/phase2_task2/sensitivity_matrix/matrix04.cfm, accessed September 16, 2014.

78 FHWA, 2012c. "III(a) Precipitation - Summary,” available at www.fhwa.dot.gov/environment/climate_change/ adaptation/ongoing and_current_research/gulf_coast_study/phase2_task2/sensitivity_matrix/matrix06.cfm, accessed September 16, 2014.

79 DOT, 2014. “Natural Gas Transmission and Gathering Incident Data - 2002 to December 2009 (ZIP),” available at http://phmsa.dot.gov/portal/site/PHMSA/menuitem.6f23687cf7b00b0f22e4c6962d9c8789/ ?vgnextoid=fdd2dfa122a1d110VgnVCM1000009ed07898RCRD\&vgnextchannel=3430fb649a2dc110VgnVCM1 000009ed07898RCRD\&vgnextfmt=print, accessed September 30, 2014.

80 Fish, D.J., undated. Freeze Protection for Natural Gas Pipeline Systems and Measurement Instrumentation, available at http://asgmt.com/wp-content/uploads/pdf-docs/2007/1/057.pdf, accessed September 30, 2014.

81 DOT, undated. The State of the National Pipeline Infrastructure, A Preliminary Report, available at https://opsweb.phmsa.dot.gov/pipelineforum/docs/Long\%20Version\%20Preliminary\%20Report\%20on\%20 Infrastructure\%20040711draftwDecadeCauseCharts.pdf, accessed September 30, 2014.

${ }^{82}$ FHWA, 2012d. "IV(b) Temperature - Additional Detail," available at www.fhwa.dot.gov/environment/ climate_change/adaptation/ongoing_and_current_research/gulf_coast_study/phase2_task2/sensitivity_matrix/ matrix09.cfm, accessed September 30, 2014. 


\section{Interdependencies}

Many of the hazards considered in this report could disrupt the other infrastructure and economic sectors upon which operation of natural gas subsector depends. These dependencies are identified in this section. However, discussion of how these hazards could disrupt liquid fuels and electric power infrastructure is contained within the two companion papers.

Several taxonomies have been created to categorize interdependencies. Researchers at Los Alamos National Laboratory described infrastructure interdependencies as a physical, logical, or functional connection from one infrastructure to another. ${ }^{83}$ Rinaldi, Peerenboom, and Kelly define interdependencies by using the following four general categories: physical, cyber, geographic, and logical. ${ }^{84}$ Pederson, Dudenhoeffer, Hartley, and Permann use the following five categories to define interdependencies: physical, informational, geospatial, policy/procedural, and societal. ${ }^{85}$ Table 5 provides definitions for the four general interdependency categories defined by Rinaldi, Peerenboom, and Kelly; and Table 6 lists the interdependency categories defined by Pederson, Dudenhoeffer, Hartley, and Permann. As these definitions show, interdependencies can vary widely with differing characteristics of the infrastructures.

For example, types of physical interdependencies for the petroleum infrastructure include the dependence of pipeline pumps, distribution terminals, and refineries on electric power. Conversely, pump stations are wired to serve as generators, and refineries can be used to produce power.

One example of a logical interdependency is the lack of alignment of operating days between the natural gas and electric industries, with the timeframe for nominating natural gas transportation service being not synchronized with the timeframe during which generators receive confirmation of their bids in the power market.

The nation's energy infrastructure underpins all other lifeline infrastructures. Without exception, every sector depends on electric power to function. Natural gas and liquid fuels require electric power to deliver product. In turn, the electric power infrastructure depends on natural gas and liquid fuels to generate power. ${ }^{86}$ Natural gas has become an increasingly popular fuel choice for electric generators. ${ }^{87}$ Concurrently, compressors used in the production and transportation of

${ }^{83}$ IEISS Technical Reference Manual, 2003, Los Alamos National Laboratory, LA-UR-03-1317.

${ }^{84}$ Rinaldi, S.M., et al., 2001, “Identifying, Understanding, and Analyzing Critical Infrastructure Interdependencies,” IEEE Control Systems Magazine, December, available at http://user.it.uu.se/ bc/Art.pdf, accessed September 23, 2014.

85 Pederson, P., et al., 2006, Critical Infrastructure Interdependency Modeling: A Survey of U.S. and International Research, INL/EXT-06-1144, Idaho National Laboratory, August, available at www.inl.gov/technicalpublications/Documents/3489532.pdf, accessed September 3, 2014.

86 Royal Academy of Engineering, 2011, Infrastructure, Engineering and Climate Change Adaptation - Ensuring Services in an Uncertain Future, available at www.raeng.org.uk/publications/reports/engineering-the-future, accessed September 23, 2014.

87 EIA, 2015. "Scheduled 2015 Capacity Additions Mostly Wind and Natural Gas; Retirements Mostly Coal,” available at http://www.eia.gov/todayinenergy/detail.cfm?id=20292, accessed April 20, 2015. 
Table 5: Principal Interdependency Categories Defined by Rinaldi et al. (2001) ${ }^{88}$

\begin{tabular}{|l|l|}
\multicolumn{1}{|c|}{$\begin{array}{c}\text { Interdependency } \\
\text { Category }\end{array}$} & $\begin{array}{l}\text { Definition } \\
\text { Physical }\end{array}$ \\
\hline Cyber & $\begin{array}{l}\text { A physical linkage between infrastructures in which the state of each infrastructure is } \\
\text { dependent on the material output(s) of the other } \\
\text { infrastructure }\end{array}$ \\
\hline Geographic & $\begin{array}{l}\text { A local environmental event affects components across multiple infrastructures due to their } \\
\text { physical proximity }\end{array}$ \\
\hline Logical & $\begin{array}{l}\text { The state of each infrastructure depends on the state of the other via a mechanism that } \\
\text { does not fall into one of the above categories }\end{array}$ \\
\hline
\end{tabular}

Table 6: Interdependency Categories Defined by Pederson et al. (2006) ${ }^{89}$

\begin{tabular}{|l|l|}
\hline \multicolumn{1}{|c|}{$\begin{array}{c}\text { Interdependency } \\
\text { Category }\end{array}$} & \multicolumn{1}{c|}{ Definition } \\
\hline Physical & $\begin{array}{l}\text { A requirement, often engineering reliance between components. For example: a tree } \\
\text { falls on a power line during a thunderstorm resulting in a loss of power to an office } \\
\text { building and all the computers inside. }\end{array}$ \\
\hline Informational & $\begin{array}{l}\text { An informational or control requirement between components. For example: a SCADA } \\
\text { system that monitors and controls elements on the electrical power grid. A loss of the } \\
\text { SCADA system will not, by itself, shut down the grid, but the ability to remotely monitor } \\
\text { and operate the breakers is lost. }\end{array}$ \\
\hline Geospatial & $\begin{array}{l}\text { A relationship that exists entirely because of the proximity of components. For example, } \\
\text { flooding or a fire may affect all the assets located in one building or area. }\end{array}$ \\
\hline Policy/Procedural & $\begin{array}{l}\text { An interdependency that exists due to policy or procedure that relates a state or event } \\
\text { change in one infrastructure sector component to a subsequent effect on another } \\
\text { component. }\end{array}$ \\
\hline Societal & $\begin{array}{l}\text { The interdependencies or influences that an infrastructure component event may have } \\
\text { on societal factors, such as public opinion, public confidence, fear, or cultural issues. } \\
\text { Even if no physical linkage or relationship exists, consequences from events in one } \\
\text { infrastructure may affect other infrastructures. }\end{array}$ \\
\hline
\end{tabular}

natural gas have come to rely increasingly on electricity rather than natural gas for their power source,. ${ }^{90}$ T.D. O’Rourke provides a reasonable explanation of interdependency:

Lifeline systems all influence each other. Electric power networks, for example, provide energy for pumping stations, storage facilities, and equipment control for transmission and distribution systems for oil and natural gas. Oil provides fuel and lubricants for generators, and natural gas provides energy for generating stations, compressors, and storage, all of which are necessary for

${ }^{88}$ Rinaldi, S.M., et al., 2001, “Identifying, Understanding, and Analyzing Critical Infrastructure Interdependencies,” IEEE Control Systems Magazine, December, available at http://user.it.uu.se/ bc/Art.pdf, accessed September 23, 2014.

89 Pederson, P., et al., 2006, Critical Infrastructure Interdependency Modeling: A Survey of U.S. and International Research, INL/EXT-06-1144, Idaho National Laboratory, August, available at www.inl.gov/technicalpublications/Documents/3489532.pdf, accessed September 23, 2014.

90 FERC, 2011, “Outages and Curtailments during the Southwest Cold Weather Event of February 1-5, 2011," Washington, D.C., August, available at www.ferc.gov/legal/staff-reports/08-16-11-report.pdf, accessed September 23, 2014. 
the operation of electric power networks. This reciprocity can be found among all lifeline systems. ${ }^{91}$

\subsection{Energy Infrastructure Context}

Interconnected and interdependent energy infrastructures are extremely complex systems that involve physical facilities (power plants, refineries, etc.), increasingly cyber-dependent control and communication systems, transmission lines, phone lines, roadways, railways, waterways, etc., and human decision makers (e.g., consumers, legislators, investors, CEOs). ${ }^{92}$ Figure 10 provides a high-level view of interconnected critical infrastructures.

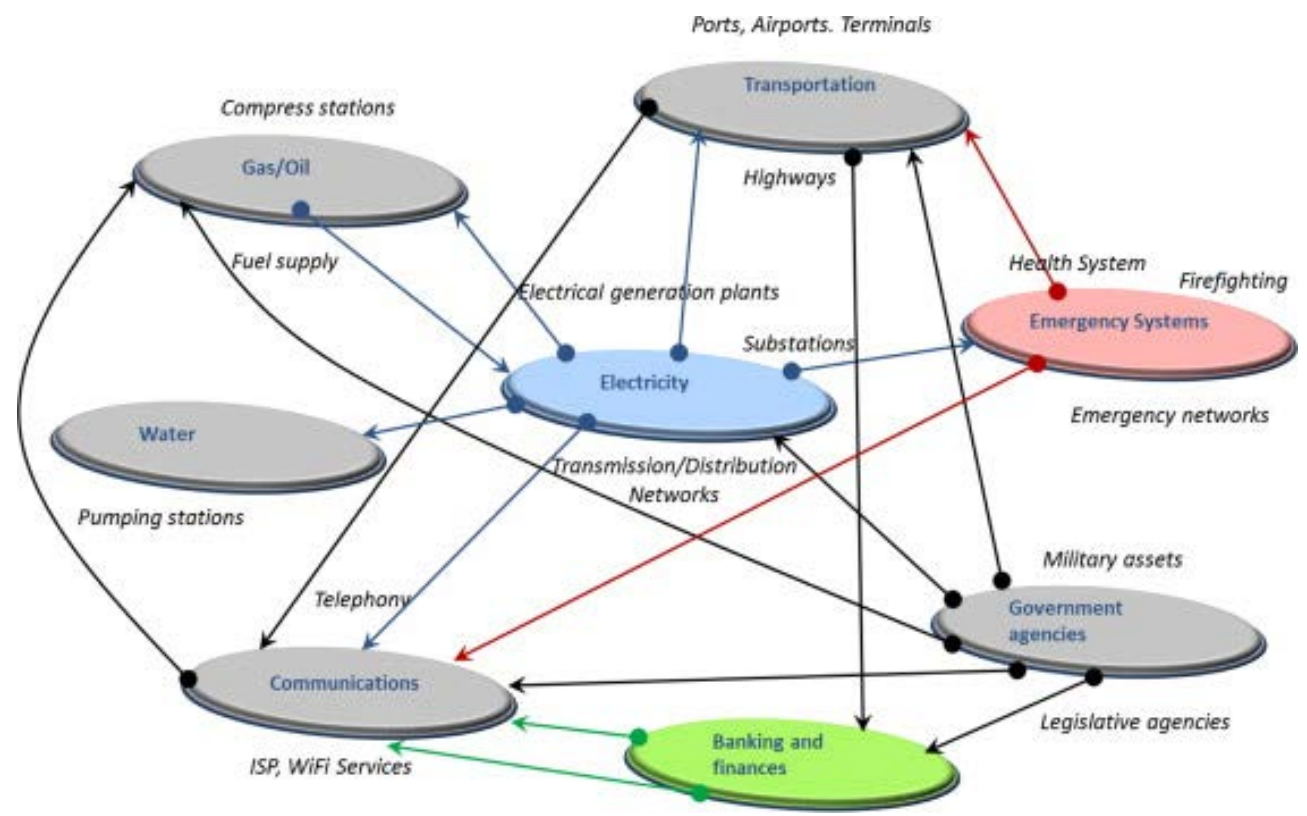

Figure 10: Infrastructure Dependencies and Interdependencies ${ }^{93}$

The U.S. energy infrastructure comprises four key components: (1) resource extraction and processing infrastructure, such as equipment to extract and refine coal, natural gas, and oil; (2) fuel transportation and storage infrastructure, including physical networks of natural gas and crude and refined oil pipelines; (3) electricity generation infrastructure, including coal-fired, gasfired, and nuclear power plants, as well as a renewable energy infrastructure; and (4) electricity transmission and distribution infrastructure, such as power lines that transport energy to consumers. According to the U.S. Department of Energy (DOE), the energy supply chain has

${ }^{91}$ O’Rourke, T. D., 2007, “Critical Infrastructure, Interdependencies, and Resilience,” Bridge-Washington-National Academy of Engineering 37, No. 1, p. 22, available at http://pdf.aminer.org/000/243/970/ robust_and_resilient_critical_infrastructure_systems.pdf, accessed September 23, 2104.

${ }^{92}$ IEISS Technical Reference Manual, 2003, Los Alamos National Laboratory, LA-UR-03-1317.

${ }^{93}$ Reality Based Training \& Exercises, Energy Industry, available at http://www.rbtxllc.com/energy-industry.html, accessed on April 20, 2015. 
grown increasingly complex and interdependent. In total, the U.S. energy supply chain includes approximately 2.6 million miles of interstate and intrastate pipelines, 6,600 operational power plants, about 144 operable refineries, and about 160,000 miles of transmission lines. ${ }^{94}$

The following highlights key interdependencies between the natural gas sector and other infrastructures.

\subsection{Interdependencies among Oil, Natural Gas, and Electric Power}

The oil, natural gas, and electric power infrastructures are interdependent. Natural gas compressors and processing plants depend on electric power for standard operations. Electric power, in turn, depends on natural gas as fuel for generation plants. Currently, $31 \%$ of all natural gas produced in the United States is used to fuel electric power generation plants. ${ }^{95}$ Refineries depend on electric power to run various items of equipment, such as distillation units, catalytic crackers, and coking units. Refineries also consume natural gas as a fuel in the refining process. ${ }^{96}$ Natural gas is also needed in pipeline operations and to run compressor stations. Figure 11 details the interdependent links among oil, natural gas, and electric power.

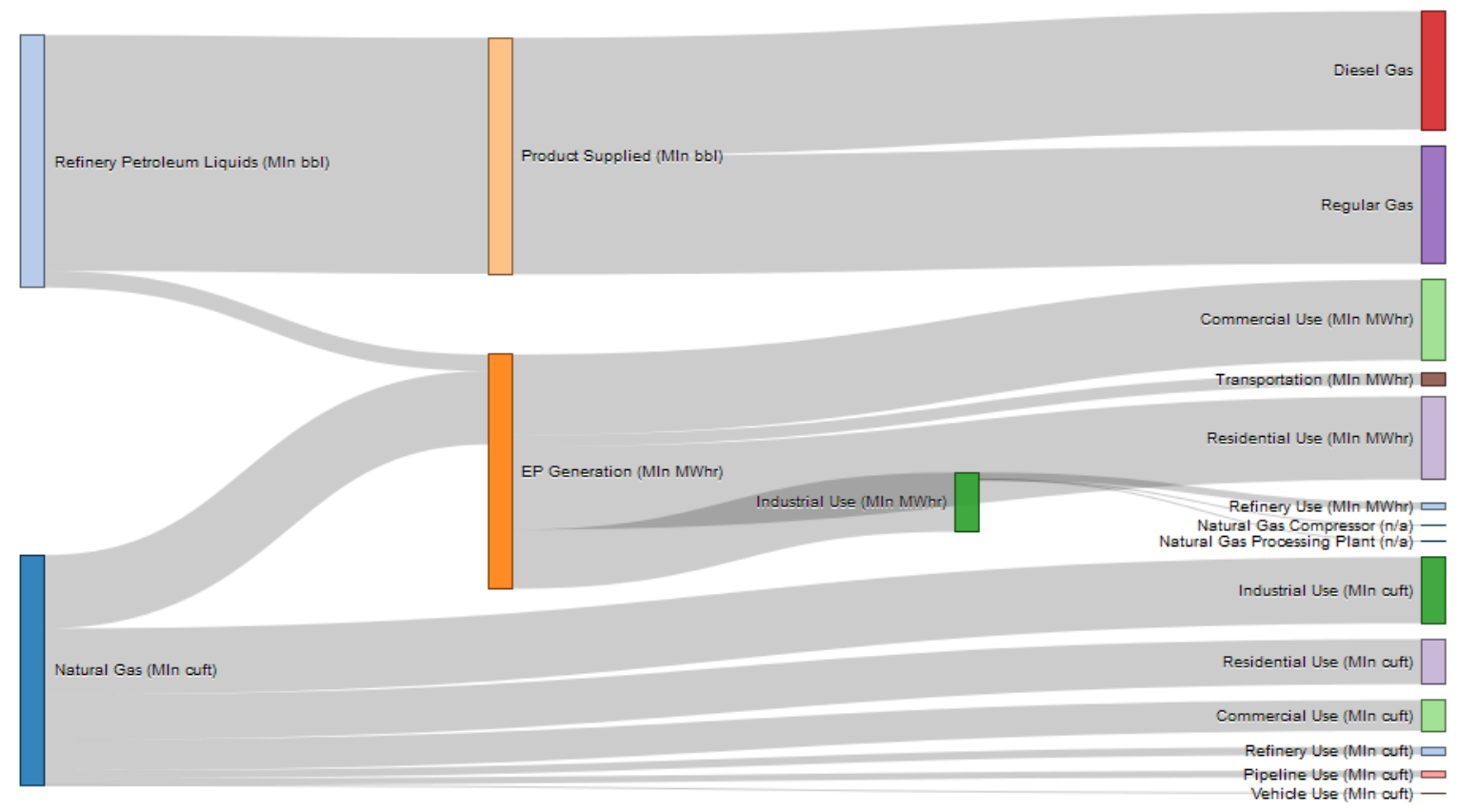

Figure 11: Interdependent Links among Oil, Natural Gas, and Electric Power

${ }^{94}$ GAO (U.S. Government Accountability Office), 2014, Climate Change: Energy Infrastructure Risks and Adaptation Efforts, January, www.gao.gov/assets/670/660558.pdf, accessed September 24, 2014.

95 EIA, undated d, “Electric Power Monthly Data for July 2014, Release Date: September 25, 2014,” available at www.eia.gov/electricity/monthly/epm_table_grapher.cfm?t=epmt_2_4_a, and EIA, undated e, "Natural Gas Gross Withdrawals and Production, available at www.eia.gov/dnav/ng/ng_prod_sum_dcu_NUS_a.htm, accessed October 17, 2014.

96 EIA, undated f, “Fuel Consumed at Refineries,” available at www.eia.gov/dnav/pet/pet_pnp_capfuel_dcu_nus_a.htm, accessed October 17, 2014. 


\subsubsection{Electric Power and Natural Gas}

Approximately 31\% of all natural gas produced is used to generate electricity in natural-gas-fired generation plants. It is unclear, however, what portion of electric power is used to run compressor stations and processing plants. This is currently a data gap, but information on electric use by compressor stations can be collected from FERC Form 2 (Major Natural Gas Pipeline Annual Reports). ${ }^{97}$ Similar information on the electric demand of natural gas processing plants is not collected by the EIA. ${ }^{98}$

The dependencies of the natural gas TS\&D sector on electricity include the following:

- Electricity for propane-air peak shaving plants;

- Electricity for LNG storage facilities;

- Electricity for electric power compressor stations; and

- Electricity for dehydrating underground stored gas ${ }^{99}$ (pipeline-quality gas is pumped down the hole, and when it is withdrawn, it requires processing to remove water from the natural gas and filtration all over again.

A propane-air peak-shaving plant is an alternate source of energy in the event that the natural gas source becomes unavailable. Many utility companies use liquid propane mixed with air to duplicate the properties of natural gas. This mixed gas is then used to supplement the local distribution companies' (LDCs') gas supply, allowing for a more consistent fuel rate from the supplier to help meet peak-demand loads. ${ }^{100}$ This plant contains electric-driven equipment (e.g., a pump to transfer the liquid propane to the vaporizer), for which the electricity is typically provided by the grid. The loss of commercial electric power would halt plant operations (unless the plant had a backup generator).

Traditionally, LNG facilities have used gas turbines to drive their refrigeration compressors. ${ }^{101}$ A modern 6-8 million tons per annum (MTPA) LNG liquefaction plant typically requires four large compressors with 60-80 MW of rotating shaft power. This power can be provided either by

97 FERC, 2014. "Form 2/2A - Major and Non-Major Natural Gas Pipeline Annual Report, Data (Current and Historical),” available at http://www.ferc.gov/docs-filing/forms/form-2/data.asp, accessed October 27, 2014.

98 EIA, 2014c. Natural Gas Processing Plant Survey, Form EIA-757, Schedule A: Baseline Report, available at http://www.eia.gov/ survey/form/eia_757/form_a.pdf, accessed October 7, 2014.

99 Netusil, M., and P. Ditl, 2011. “Comparison of Three Methods for Natural Gas Dehydration,” Journal of Natural Gas Chemistry 20, pp. 471-476, available at http://ac.els-cdn.com/S1003995310602186/1-s2.0-

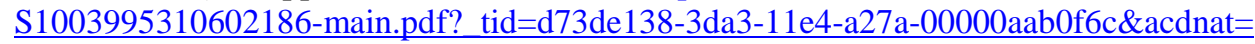
1410873642_a41ae3ee8d37bee386876d0b6c25b927, accessed September 16, 2014.

100 Alternate Energy Systems, Inc., undated. "Natural Gas Peak Shaving,” available at http://www.peakshaving.com/Technology/Tech.htm, accessed September 16, 2014.

101 Breistein, H., 2009. Fixed Speed Electric Motor Drives for LNG Refrigeration Compressors, Norwegian University of Science and Technology, June, available at http://www.diva-portal.org/smash/get/diva2:348804/ FULLTEXT01.pdf, accessed October 3, 2014. 
gas turbines or an electric drive. A 4-MTPA LNG facility has a power requirement equal to that of an industrialized city of about 100,000 inhabitants. In general, most general utility companies provide the power by extending their existing (triple cycle) facilities (e.g., with a gas-for-power outsourcing arrangement). ${ }^{102}$

Most compressor stations are fueled by a portion of the natural gas flowing through the station, although in some areas of the country, all or some of the units may be electrically powered primarily for environmental or security reasons. ${ }^{103}$ Figure 12 shows that a small percentage of compressor stations are electric-driven.

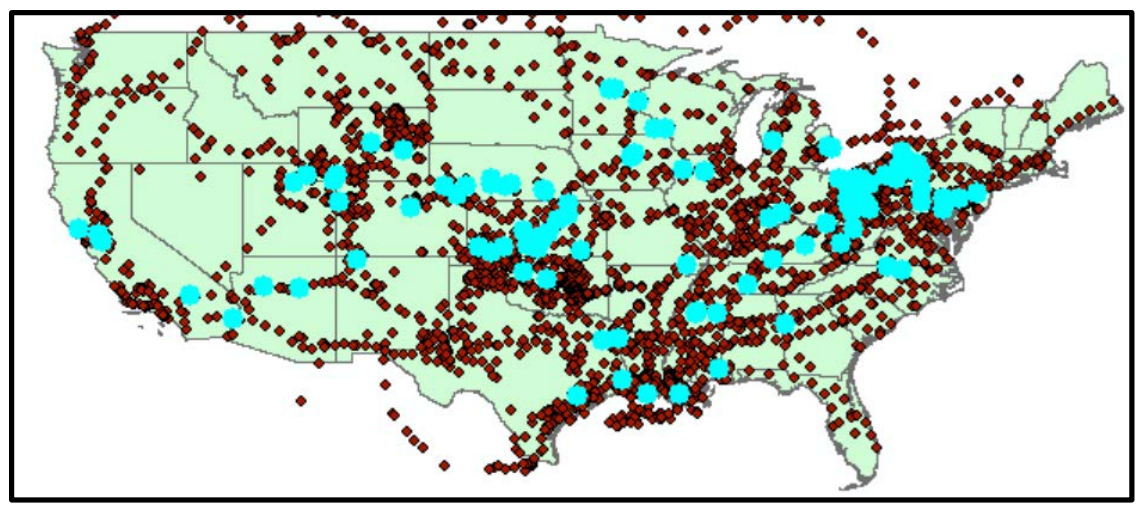

Figure 12: Locations of Electric-Driven Compressor Stations (blue dots) (Red diamonds indicate natural-gas-driven compressor stations.)

The U.S. electricity sector is experiencing its biggest transformation in half a century, as power companies retire many aging, economically uncompetitive coal-fired power plants. In 2008, coal generated 48 percent of the nation's power. In 2012, it provided only 37 percent. Natural gas is replacing most of this coal-fired power. From 2008 to 2012, the amount of electricity generated from natural gas increased more than 50 percent. In 2013, 27 percent of U.S. electricity was fueled by natural gas. ${ }^{104}$ If current trends continue, it is projected that natural gas will account for nearly two-thirds of U.S. electricity by $2050 .{ }^{105}$

102 ABB, 2006. All Electric LNG Plants, Better, Safer, More Reliable - and Profitable, available at http://www05.abb.com/global/scot/scot216.nsf/veritydisplay/9e770a172afc8d7ec125779e004b9974/\$file/paper\% 20lng_rev\%20a_lowres.pdf, accessed October 3, 2014.

103 EIA, 2007. Natural Gas Compressor Stations on the Interstate Pipeline Network: Developments since 1996, available at http://www.eia.gov/pub/oil_gas/natural_gas/analysis_publications/ngcompressor/ngcompressor.pdf, accessed September 16, 2014.

${ }^{104}$ EIA, 2014. "Electricity in the U.S.,” available at http://www.eia.gov/energyexplained/index.cfm? page=electricity_in the united_states, accessed September 16, 2014.

105 Union of Concerned Scientists, 2013. The Climate Risks of an Overreliance on Natural Gas for Electricity, October, available at http://www.ucsusa.org/clean_energy/our-energy-choices/coal-and-other-fossilfuels/natural-gas-climate-change.html 


\subsubsection{Oil and Natural Gas}

Oil refineries depend on natural gas as a fuel source. The natural gas infrastructure does not rely on oil to run, but it is dependent on oil at the production wellheads. Table 7 shows natural gas and electricity consumed at refineries in 2013 by Petroleum Administrative Defense District (PADD). The map in Figure 13 shows the PADDs.

Petroleum products are produced from processing crude oil at petroleum refineries and extracting liquid hydrocarbons (i.e., NGLs) at natural gas processing plants. The expected growth of NGLs has important implications for the U.S. oil refining sector, since the NGLs will potentially displace refinery-produced naphtha or liquefied petroleum gas (LPG). It is forecast that NGL production will roughly double by 2025, rising to about 6 million barrels per day (bpd), depending on transport capability and markets for the liquids. ${ }^{106}$

Natural gas can be compressed (compressed natural gas or CNG) or converted into liquid fuel (LNG) fuel to use in place of conventional fuels in modified engines or o be used in fuel cell vehicles. Globally, there are more than 15 million natural gas vehicles, and almost three-quarters of those are in just five countries: Pakistan, Argentina, Brazil, Iran, and India. In 2010, CNG and LNG vehicles represented about 0.05 percent (about 120,000 vehicles) of the U.S. vehicle stock.

\subsubsection{Other Infrastructures and Natural Gas}

The natural gas TS\&D sector depends on other infrastructures (such as information technology, telecommunications for SCADA and Control, banking and finance, transportation, and water) to operate. Likewise, these other infrastructures depend on the natural gas infrastructure. ${ }^{107}$ The heavy reliance on pipelines to distribute products across the nation highlights the interdependencies between the Energy and Transportation Systems Sectors.

Table 7: Fuels Consumed at Refineries in $2013^{108}$

\begin{tabular}{|c|c|c|}
\hline PADD & $\begin{array}{c}\text { Natural Gas } \\
\text { (Million Cubic Feet) }\end{array}$ & $\begin{array}{c}\text { Electricity } \\
\text { (Million MWh) }\end{array}$ \\
\hline 1 & 49,034 & 2.4 \\
\hline 2 & 150,414 & 12.2 \\
\hline 3 & 491,023 & 24.6 \\
\hline 4 & 29,475 & 2.1 \\
\hline 5 & 177,103 & 4.8 \\
\hline Total & 897,049 & 46.1 \\
\hline
\end{tabular}

106 The INGAA Foundation, Inc., 2014. “Executive Summary,” North American Midstream Infrastructure through 2035: Capitalizing on Our Energy Abundance, prepared by ICF International, available at http://www.ingaa.org/File.aspx?id=21498, accessed September 16, 2014.

107 DOE and DHS, 2010. Energy Sector-Specific Plan - An Annex to the National Infrastructure Protection Plan, available at http://www.dhs.gov/xlibrary/assets/nipp-ssp-energy-2010.pdf, accessed September 16, 2014.

${ }^{108}$ EIA, undated g, "Fuels Consumed at Refineries by PAD District, 2013,” Refinery Capacity 2014, available at http://www.eia.gov/petroleum/refinerycapacity/table10.pdf, accessed October 17, 2014. 


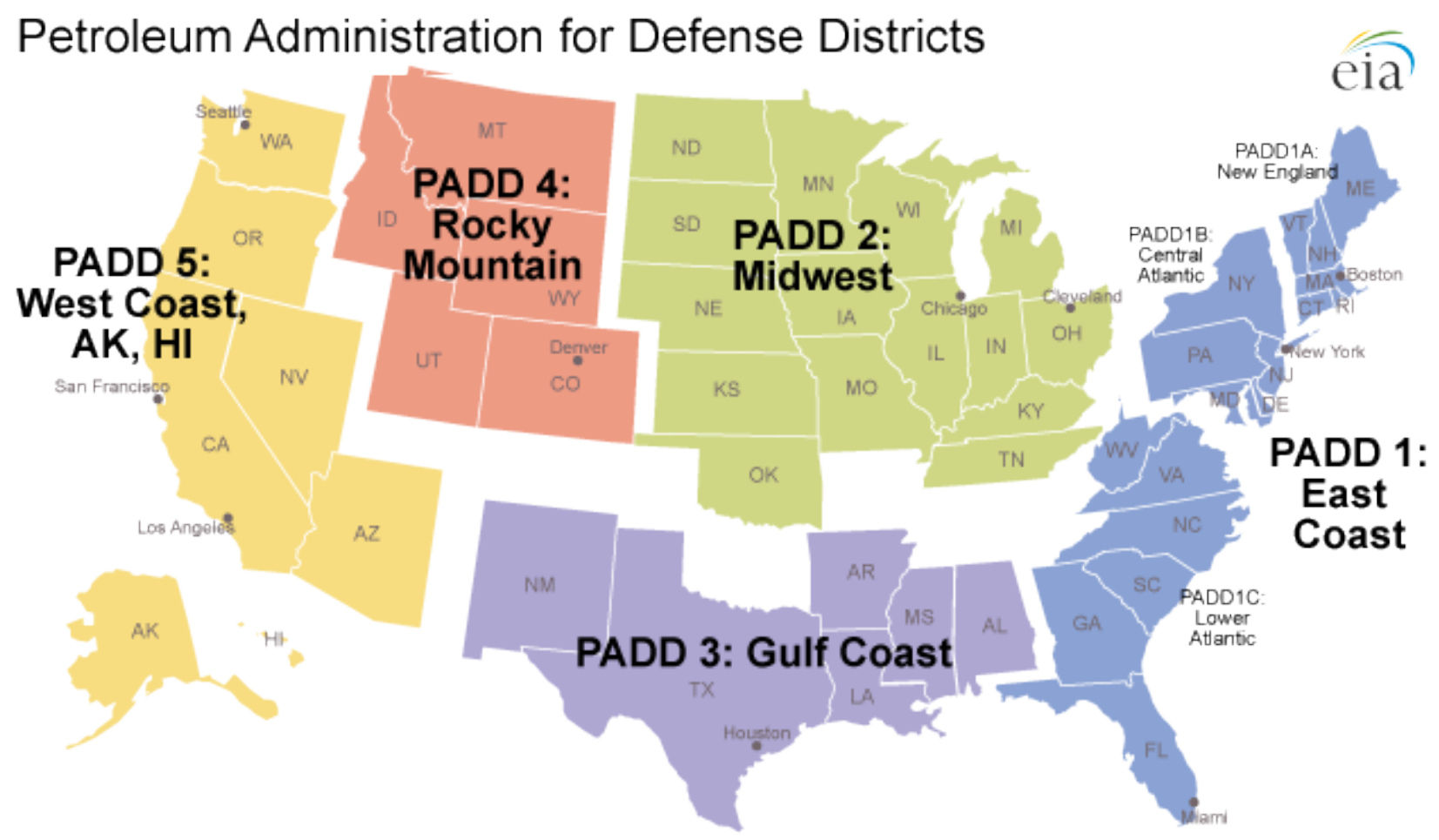

Figure 13: U.S. PADDs ${ }^{109}$

To monitor and control the flow of natural gas, centralized gas control stations collect, assimilate, and manage data received from compressor stations all along the pipeline. These control systems can integrate gas flow and measurement data with other accounting, billing, and contract systems. Most of the data that are received by a control station are provided by SCADA systems. The data are transmitted through a communications network that can consist of company-owned fiber-optic lines, leased telephone lines, ground- or satellite-based microwave systems, or radio communication systems. ${ }^{110}$ The total loss of communications could result in manual operations for the affected pipeline.

The dependencies of other infrastructures on the natural gas TS\&D sector include the following:

- Supply of natural gas for electric generation,

- Supply of natural gas liquids (NGLs) for petroleum refining, and

- Natural gas as a transportation fuel.

The use of natural gas in North America has increased over the past decade, particularly in the power-generation sector, where natural gas has become a fuel of choice. In addition, there has been a resurgence of gas use in industrial applications due to the relatively low gas prices that

109 EIA, undated h, "PADD Regions Enable Regional Analysis of Petroleum Product Supply and Movements,” Today in Energy, available at www.eia.gov/todayinenergy/detail.cfm?id=4890, accessed October 17, 2014.

110 Folga, S., 2007. Natural Gas Pipeline Technology Overview, available at http://corridoreis.anl.gov/documents/docs/technical/APT_61034_EVS_TM_08_5.pdf, accessed September 16, 2014. 
have prevailed during the past few years, while the growing production of NGLs has stimulated renewed interest in petrochemicals production, for which ethane and propane are key feedstocks. Meanwhile, growing oil production from unconventional sources has created opportunities for North American refineries to take advantage of crude supplies from various sources. ${ }^{111}$

Although the taxonomies just discussed provide a starting point for describing and discussing interdependencies, actual interdependent events are complex, as illustrated by the highly visible case studies that follow here.

\subsection{Case Study of a Disruptive Event: The Big Chill}

The Southwest Region of the United States experienced unusually cold and windy weather during the first week of February 2011. Lows during the period were in the teens for five consecutive mornings, and there were many sustained hours of below-freezing temperatures throughout Texas and in New Mexico. Low temperatures in Albuquerque, New Mexico, ranged from $7^{\circ}$ to $-7^{\circ} \mathrm{F}$ over the period; the average high is $51^{\circ} \mathrm{F}$, and the average low is $26^{\circ} \mathrm{F}$. Temperatures in Dallas ranged from $14^{\circ}$ to $19^{\circ} \mathrm{F}$, compared to an average high of $60^{\circ} \mathrm{F}$ or above and average lows in the mid to upper 30s. ${ }^{112}$

During the cold snap, electric entities located within the Texas Reliability Entity, Inc., the Western Electricity Coordinating Council, and the Southwest Power Pool were affected by the extreme weather, as were gas entities in Texas, New Mexico, and Arizona. The cold temperatures affected gas deliveries on the El Paso Natural Gas system in New Mexico. Natural gas production was limited due to freeze-offs and equipment issues. Power plants also had equipment issues, which led to rolling blackouts and more loss of natural gas supply. More than 30,000 customers experienced natural gas outages at some point during this period. ${ }^{113}$

The majority of the problems experienced by the many generators that tripped, suffered derating, or failed to start during the event were attributable, either directly or indirectly, to the cold weather itself. For the Southwest as a whole, 67 percent of the generator failures (by MWh) were due directly to weather-related causes, including frozen sensing lines, frozen equipment, frozen water lines, frozen valves, blade icing, low-temperature cutoff limits, and the like. At least another 12 percent were indirectly attributable to the weather (occasioned by natural gas curtailments to gas-fired generators and difficulties in fuel switching). Low temperatures returned to the region on February 10, 2011. In fact, the Electric Reliability Council of Texas (ERCOT) set a new winter peak that day. But no load shedding proved necessary, largely because the temperatures were not quite as cold or sustained as those of the previous week, the winds were less severe, and many of the repairs and protective measures taken by the generators on February 2 remained in place.

\footnotetext{
111 INGAA (Interstate Natural Gas Association of America), 2014. North America Midstream Infrastructure through 2035: Capitalizing on Our Energy Abundance, available at http://www.ingaa.org/Foundation/Foundation-Reports/2035Report.aspx, accessed September 16, 2014.

112 Ibid.

113 Ibid.
} 
This example of natural gas freeze offs and cascading impacts to electric power illustrates the complex relationship between natural gas and electric power, which had compounding effects during a period of extreme weather.

\subsection{Case Study of a Disruptive Event: Coordinating Natural Gas and Electric Power}

Weather events in January 2014 provide an example of the challenges of electricity and natural gas coordination. On January 7, during a polar vortex cold weather event, electricity system operators across the eastern half of the United States struggled to maintain reliability. In particular, PJM, the electricity system operator (an independent system operator) responsible for the Mid-Atlantic region, experienced record demand and simultaneously with high forced-outage rates for generators due to mechanical failures and fuel supply issues.

Of the 22 percent of PJM's generation capacity that was unavailable to meet peak load, a quarter of the outages were due to the inability or unwillingness of gas generators to secure natural gas transportation nominations. This was a result of the tremendous heating load and commensurate lack of available interruptible capacity on the pipeline system. ${ }^{114}$

PJM set a new wintertime peak demand record of 141,846 MW during the evening of January 7, while it was dealing with higher-than-normal generation outages. During the peak-demand hour, 22 percent of the generation capacity-including coal, gas, and nuclear-was out of service.

The generation forced outage rate was two to three times higher than the normal peak winter outage rate of around 7-10 percent. Equipment issues associated with both coal and natural gas units caused the greatest proportion of forced outages. Natural gas interruptions represented about 25 percent of the total outages.

Synchronized reserves (those supplied to the system from resources that are synchronized/connected to the grid and able to load within 10 minutes) were at their lowest point the morning of January 7. For a five-minute period, synchronized reserves were reduced to about $500 \mathrm{MW}$, compared to a PJM requirement of 1,372 MW. Because other reserves were available, PJM added an additional 1,167 MW of primary reserves (reserves available in 10 minutes but not synchronized/connected to the grid) for a total of 1,667 MW of 10-minute reserves at the lowest point of the hour. ${ }^{115}$

A second, longer, cold weather period in January 2014 also challenged the PJM system and operators. Prolonged cold temperatures from January 17 to 29 combined with a snowstorm that dropped about a foot of snow on the East Coast. During the polar vortex, power supply issues centered on the unavailability of generation because of forced outages. During this second cold

114 DOE, 2014. “July 28 Stakeholder Meeting on Natural Gas - Electricity Interdependence,” July 24, available at http://energy.gov/sites/prod/files/2014/07/f17/qermeeting_denver_backgroundmemo.pdf.

${ }^{115}$ PJM Interconnect, 2014. "Analysis of Operational Events and Market Impacts during the January 2014 Cold Weather Events,” May 8, available at www.pjm.com/ /media/documents/reports/20140509-analysis-ofoperational-events-and-market-impacts-during-the-jan-2014-cold-weather-events.ashx. 
period, the key contributor to operational challenges was scheduling natural-gas-fired generation to meet demand. ${ }^{116}$

${ }^{116}$ Ibid. 


\section{Options for Mitigation, Preparedness, Recovery, and Response}

The natural gas industry responds quickly and well to threats created by natural disasters and other physical events. Historically, although individual companies have not experienced widespread emergencies (like the outages historically experienced by electric utilities, which can involve hundreds of thousands of customers), they have done a good job in responding to problems and restoring service to customers. Most companies understand and are able to handle their own physical infrastructure problems. Prudent business practices require the industry to quickly respond to physical incidents caused by natural events (earthquakes, hurricanes, etc.) and man-made events (vandalism, criminal activity, terrorism, accidents, etc.).

As part of this effort, response and recovery planning, in conjunction with obtaining timely information on threats and vulnerabilities, play a major role in mitigating business risks for the natural gas industry.

When infrastructure disruptions occur, the roles and responsibilities of local, state, and federal governments often conflict. These conflicts of interest regarding jurisdiction impede the timely restoration of service and can also inhibit the timely development of infrastructure protection processes. Timely and actionable information is important for effective responses to threats or incidents as well as for successful recovery actions. Companies can benefit by having an effective internal information-sharing mechanism to receive, analyze, and disseminate incident information to enhance response and recovery. ${ }^{117}$

Despite system redundancies, transmission and distribution pipelines can be vulnerable to significant damage from natural and man-made disasters. Identifying an alternative supply of fuel for comfort heating and/or power generation, whose availability does not depend on pipelines, is critically important for facilities that will play important and life-sustaining roles in the aftermath of major seismic events. To mitigate against this damage, the following options can be considered:

- The potentially affected natural gas utility should be supported in making the modifications to its natural gas distribution infrastructure that are needed to accommodate storage from LNG and propane-air facilities. Although these types of storage are much more expensive than those used for seasonal storage, they are still are less costly than the long-haul transmission infrastructure supporting a peak-day delivery.

- Installation of a propane-air systems and a CNG storage system at critical infrastructure facilities can insulate those facilities from interruptions in pipeline-supplied natural gas.

117 National Petroleum Council, 2001. Securing Oil and Natural Gas Infrastructures in the New Economy, available at http://www.npc.org/, accessed September 15, 2014. 
- The potentially-affected transmission pipeline should be supported in making the modifications to its natural gas transmission infrastructure that are needed to accommodate reversing the flow of gas through the pipeline (i.e., to allow natural gas to flow counter to normal flow conditions).

- A new gas source (e.g., an LNG facility) that could connect with the existing transmission pipeline system could be established.

As appropriate, critical facility owners and operators should develop business continuity plans to improve the likelihood that essential operations will be maintained or quickly recover after a long-term loss of electric power or natural gas. These could include memoranda of agreement with the electric power and natural gas companies to provide priority restoration of services; provisions for conducting exercises on how to respond to a loss of critical utility services annually with the local provider; and procedures for testing emergency generators regularly at full load.

Note that the geographical diversification of energy sources away from hurricane-prone areas like the Gulf of Mexico has reduced their vulnerability to hurricanes. The EIA reports that the percentage of natural gas production from the Gulf of Mexico shifted from 20 percent in 2005 to 7 percent in 2012 due to the development of shale gas production in other parts of the United States. $^{118}$

118 EIA, 2013. "Hurricane effects on oil and natural gas production depend on storm trajectory, strength," available at http://www.eia.gov/todayinenergy/detail.cfm?id=11491, accessed May 27, 2015. 


\section{Key Gaps}

The following sections present some key gaps identified during the development of this report.

\subsection{Knowledge}

To better understand potential climate change impacts on the transportation infrastructure and to identify adaptation strategies, DOT is conducting a comprehensive, multiphase study of climate change impacts in the central Gulf Coast Region. A recent (June 2014) report ${ }^{119}$ identified methodologies for conducting a transportation-system-wide, climate-vulnerability assessment. Unlike reports covering other transportation modes, this report did not contain a vulnerability screen for pipelines, since most of what is known about the severe-weather-related and severeclimate-related vulnerabilities of pipelines applies only to the offshore infrastructure. Relatively significant damage occurred occasionally as a result of recent hurricanes, but other storms produced only minor damage. There is still significant uncertainty about the overall risk to pipelines from climate change, and further research is needed to determine appropriate adaptation or mitigation actions.

\subsection{Data}

The following sets of data could enhance the understanding of natural gas infrastructure issues under climate change scenarios:

- Inventory of the electricity-dependent natural gas infrastructure and of the status of the backup power contingency in production, processing, transmission, and distribution to help assess risks to the natural gas infrastructure from electrical outages;

- Geospatial data on national soil, vegetation, terrain, floodplain, and pipeline depths to identify landslide, flood, and soil saturation risks; and

- Planning scenarios for extreme weather events by region, to give infrastructure planners data on the severity and probability of extreme weather so they can develop in-system and contingency designs.

\subsection{Analytical Capabilities}

It appears that advanced methods and tools for vulnerability assessments and system analyses are needed to identify critical nodes within the natural gas TS\&D sector, examine interdependencies,

${ }^{119}$ ICF International, 2014. Impacts of Climate Change and Variability on Transportation Systems and Infrastructure, The Gulf Coast Study, Phase 2 - Screening for Vulnerability, Final Report, Task 3.1, available at https://www.fhwa.dot.gov/environment/climate_change/adaptation/ongoing_and_current_research/gulf_coast_st udy/phase2 task3/task_3.1/phase2task3.pdf, accessed September 16, 2014. 
and help gain an understanding of the behavior of this complex system. Modeling and simulation tools for determining the impacts on customers from natural gas disruptions and test beds for studying infrastructure-related problems are essential for understanding the possible responses of the natural gas TS\&D sector to emerging threats, such as climate change.

The FEMA Hazus tool is a nationally applicable, standardized methodology that contains models for estimating potential losses from earthquakes, floods, and hurricanes. ${ }^{120}$ Potential loss estimates analyzed in Hazus include physical damage to residential and commercial buildings, schools, critical facilities, and infrastructure. The Hazus tool is currently limited to estimating the possible impacts of an earthquake on underground gas pipelines. Further research is needed to extend this tool to other natural hazards (flooding, high winds) that could become more frequent under climate change conditions.

\subsection{Technology}

The natural gas/liquid supply-side chain consists of production, gas processing (cleaning the gas so impurities and liquids are removed), shipping the NGLs to petroleum refineries (and similar processing facilities), transport in transmission pipelines, and distribution to consumers. An upset within the supply chain sectors could potentially lead to downstream gas curtailments or issues. An example would be a tornado that would damage a natural gas processing plant and an NGL pipeline to a petroleum refinery. The damage from the tornado would lead to curtailments in the downstream gas supply and limit upstream gas well production. In this case, the other supply sectors would be operational but limited by one of the key value chain sectors.

The complete delivery supply chain must be considered as an entire system and its resilience must be studied to account for climate change issues.

\subsection{Policy}

The winter of 2013 was one of the worst on record for the United States. The natural gas industry may have been hit the hardest; prices rose due to the high level of demand that comes along with below-zero temperatures and diminishing supply. TransCanada Pipeline experienced a fire on the Emerson lateral on January 25, which caused prices for natural gas to skyrocket. Deliveries to many interruptible and firm natural gas customers in the Midwest were curtailed; they faced reductions in gas deliveries for hours and even days due to a shortage of supply, since demand for service exceeded capacity. Some plants and facilities were prepared; they had emergency plans in place and access to alternative fuels; others were not. As the United States continues to experience extremely severe and volatile winter weather, ${ }^{121}$ it may become a requirement for all

120 FEMA, 2014. “Hazus,” available at http://www.fema.gov/hazus, accessed on September 16, 2014.

121 Natural variability will continue to modify the long-term trend in global temperature due to human activities. (An example was the cooler years due to La Niña, such as 2011.) A new study says that as the world gets warmer, parts of North America, Europe, and Asia could experience more frequent and stronger visits of the polar vortex that occurred in 2013-2014, because of shrinking ice in the seas off Russia (USA Today, 2014. "Polar Vortex 
facilities to know what to do when faced with curtailments in the natural gas supply. Reliable plans that will illustrate how a company will operate during curtailment and also discuss the financial implications will be extremely important. When a company looks ahead at a winter weather forecast, it should have the appropriate knowledge to consider what options make the most sense. $^{122}$

The natural gas transmission pipeline industry typically does not own the natural gas it is transporting. The gas distribution companies, industrial entities, gas marketing companies, and electric generators (the demand side of the value chain) own the gas and must make arrangements with the transmission companies for its transportation. That means it is necessary for the demand-side/use-side companies to do the planning and forecasting of their gas requirements and then make arrangements with the transmission companies for transport. The transmission pipeline industry is akin now to the trucking/rail industry, as it has become a "freight hauler."

The load/supply forecasting and planning are handled by the demand-side value chain. This means there could be variances in how each company forecasts its supply requirements and how much risk each one decides to take in its supply portfolio. Note that the transmission pipeline company does not forecast winter supply requirements per se; instead, it awaits commitments/contracts for gas product transport from the demand side. This can lead to a potential vulnerability, depending on the ability of the demand-side company to plan or forecast its future natural gas demand. For example, what if company \#1 believes the winter will be warm and adjusts its supply, while company \#2 believes the winter will be cold and builds additional supply, and both companies contract with the transmission pipeline company for their forecasted supply. If there was an extremely cold winter (similar to 2013), company \#1 would be in dire need for a supply of gas and capacity on the pipeline system. Company \#1 would then seek supplies on the open market and also check that the pipeline company had the capacity to haul the product. Pipeline companies are not responsible for procuring the gas and will transport only if they have the capacity.

Less sophisticated supply forecasting, planning, and analysis by some demand-side value chain companies could lead to customer gas supply issues caused by effects from climate change that were not planned for or underestimated.

\subsection{Communication}

Better communications and coordination are needed among the energy sectors to understand how a problem in one infrastructure system could affect other systems. For example, the Northeast is

Visits to U.S. Linked to Climate Change,” available at http://www.usatoday.com/story/weather/2014/09/02/ polar-vortex-climate-change/14973047/, accessed October 27, 2014).

122 Shaw, N., 2014. “Curtailment: It Can Happen to You,” Pipeline \& Gas Journal, Vol. 241, No. 9, September, available at http://pipelineandgasjournal.com/curtailment-it-can-happen-you?utm_medium=email\&utm campaign=PGJ+September+News\&utm_content=PGJ+September+News+CID_39dd2d393b5c088c74219dbbf9 ac2c31\&utm_source=Email\%20marketing\%20software\&utm_term=Curtailment\%20It\%20Can\%20Happen\%20 To\%20You, accessed September 16, 2014. 
highly reliant on natural-gas-fueled generators; if natural gas deliveries to these plants were stopped without adequate warning, that loss of gas could affect a region's ability to produce enough electric power to meet customer demand. Shortages in natural gas supplies could also increase the cost of electric power production. Improved coordination is needed with regard to how each system actually operates and how the planning process is developed.

\subsection{Cost}

There is an often significant capital cost associated with building new infrastructure. One key question is how to incentivize increased system resilience. 


\section{Appendix A: Literature Review}

List of natural gas studies reviewed by the national laboratory team:

1. Resiliency Assessment, Alabama Poultry, U.S. Department of Homeland Security, June 2013.

2. Regional Resiliency Assessment Program Preliminary Analysis - Alaska, U.S. Department of Homeland Security, March 2011.

3. Resiliency Assessment, Arizona, U.S. Department of Homeland Security, July 2013.

4. Regional Resiliency Assessment Program Preliminary Analysis Paper - Denver, CO, March 2011/US Department of Homeland Security. US Department of Homeland Security. 2011.

5. Resiliency Assessment, Maine Assessment Phase, U.S. Department of Homeland Security, July 2012.

6. Resiliency Assessment, Minneapolis-St. Paul Commercial Facilities, U.S. Department of Homeland Security, March 2012.

7. Resiliency Assessment, Nebraska, U.S. Department of Homeland Security, July 2013.

8. Resiliency Assessment, Arizona, U.S. Department of Homeland Security, May 2014.

9. Draft Resiliency Assessment, Southeast New Hampshire, U.S. Department of Homeland Security, May 2012.

10. Resiliency Assessment, Texas Medical Center, U.S. Department of Homeland Security, July 2014.

11. Resiliency Assessment, Wyoming, U.S. Department of Homeland Security, March 2014.

12. Regional Resiliency Assessment Program Preliminary Analysis - Alaska, U.S. Department of Homeland Security, March 2011.

13. Great Miami/Katrina Hurricane Energy Infrastructure Assessment, U.S. Department of Energy, 2013.

14. Cushing Tornadoes Energy Infrastructure Assessment, U.S. Department of Energy, August 2013.

15. Earthquake along the Palos Verdes Fault Zone Impact to the Port of Long Beach, California - Energy Infrastructure Assessment, U.S. Department of Energy, September 2013.

16. White Prairie Midwest Regional Energy Assurance Exercise, 2011; U.S. Department of Energy’s Energy Assurance and Interdependency Workshop, 2013.

17. Red Earth Southern Regional Energy Assurance Exercise, 2011, U.S. Department of Energy.

18. "Modeling and Analysis: Impacts of a New Madrid Seismic Zone Earthquake on the U.S. Natural Gas Transmission System,” National Infrastructure Simulation and Analysis Center (NISAC), February 2010.

19. “Analysis of Potential Impacts of Gulf of Mexico Hurricane Combined with Oil Spill," NISAC, June 2010.

20. “Houston, Texas, Hurricane Scenario Analysis Report,” NISAC, April 2013.

21. "Analysis of Population, Infrastructure, and Economic Impacts Resulting from Morganza Spillway Flooding,” NISAC, May 2011.

22. “Southern California Wildfire Infrastructure Impacts,” NISAC, October 2007.

23. “Corpus Christi, Texas, Hurricane Scenario Analysis Report,” NISAC, July 2014. 
24. “Analytical Baseline Study for the Cascadia Earthquake and Tsunami," NISAC, November 2011.

25. “Analytical Baseline Study for a Salt Lake City Earthquake,” NISAC, 2013.

26. “St. Louis, MO, and Twin Cities, MN, Spring 2010 Flood Outlook,” NISAC, 2010.

27. "Regional Consequence Assessment Report, 2010 Dams Sector Exercise Series, Green River Valley,” NISAC, 2010.

28. "Hurricane Gustav,” NISAC, August 2008.

29. “Hurricane Ike,” NISAC, September 2008.

30. “Analysis of Infrastructure and Economic Impacts of a New England Hurricane,” NISAC, April 2014.

31. "Analysis of Southern Nevada Natural Gas and Liquid Fuels Pipeline Disruptions," NISAC, December 2010.

32. Regional Resiliency Assessment Program: Maine and Canadian Cross-Border Energy, NISAC, June 2011.

33. “Jacksonville, Florida, Hurricane Scenario Analysis Report,” NISAC, December 2013.

34. “Hurricane Scenario Analysis," New Orleans Area, NISAC, October 2012.

35. "Fast Analysis Report to U.S. Department of Homeland Security, Office of Infrastructure Protection, on Hurricane Katrina, Gulf Coast,” NISAC, 2005.

36. "The North American Natural Gas Infrastructure: How Vulnerable Is It to Natural Disasters, and What Are the Options for Consequence Mitigation?” NISAC, 2006.

37. “National Level Exercises 2011 (New Madrid),” NISAC, 2011. 


\section{Appendix B: Vulnerability, Impact/Severity Numerical Scale}

Vulnerability, Impact/Severity Numerical Scale
\begin{tabular}{|c|l|l|}
\hline $\begin{array}{c}\text { Scale } \\
\text { Level }\end{array}$ & \multicolumn{1}{|c|}{ VULNERABILITY } & \multicolumn{1}{c|}{ IMPACT/SEVERITY } \\
\hline 1 & Low & Minor \\
\hline 2 & Low-medium & Interrupting \\
\hline 3 & Medium & Significant \\
\hline 4 & Medium-high & Major \\
\hline 5 & High & Catastrophic \\
\hline
\end{tabular}

Vulnerability captures the concept of likelihood that the infrastructure component would be damaged as a result of the hazard being considered. In making an assessment of the vulnerability of a component, one considers the inherent characteristics of the infrastructure asset and whether those characteristics make it susceptible to damage as result of the hazard. For example, underground storage facilities would not be susceptible to high-wind weather events and be ranked low on the vulnerability scale; however, they would be vulnerable to subsidence/landslides and would be ranked high with respect to that hazard.

Severity captures the concept of the extent of damage to the infrastructure and the potential duration of the disruption. As such, it may include a consideration of several dimensions, including these:

- Geographic scope of the impacts: local, regional, or national;

- Health and safety: lives lost, injuries, evacuation area;

- Economic costs (direct and indirect): lost revenue, replacement cost, local/regional jobs lost, business closures;

- System performance: disruption in service, number of customers, percent of service area; duration of outage; and

- System restoration: time and difficulty of restoring the infrastructure to normal operations.

Since impact/severity, like vulnerability, is a function with multiple attributes, a quantitative analysis could yield a way to normalize the impact across the characteristics; however, since it is not possible to fully harmonize the data, expert judgment would necessarily encompass one or more of these aspects in order to make an overall assessment of severity. For example, one would assess the severity as being catastrophic if several regional analyses indicated that significant and prolonged disruptions to the regional natural gas infrastructure could create large- 
scale impacts with implications reaching nationally. Similarly, if the disruption was geographically limited in scope and of short duration, one would indicate that the severity was minimal. 



\section{Argonne}

Global Security Sciences Division

Argonne National Laboratory

9700 South Cass Avenue, Bldg. 221

Argonne, IL 60439-4854

www.anl.gov 